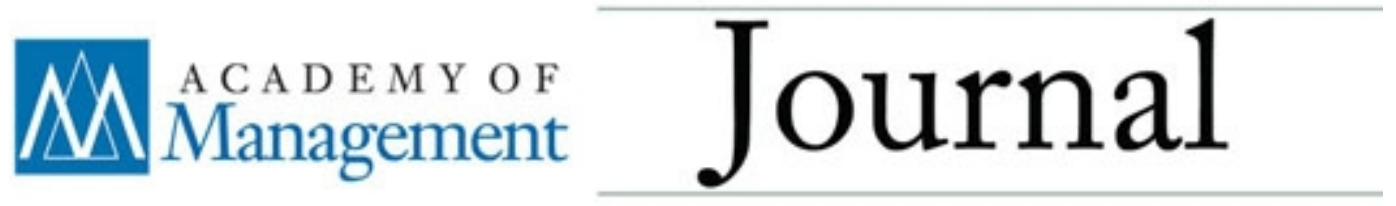

\title{
Office Chit-Chat as a Social Ritual: The Uplifting Yet Distracting Effects of Daily Small Talk at Work
}

\begin{tabular}{|c|l|}
\hline Journal: & Academy of Management Journal \\
\hline Manuscript ID & AMJ-2018-1474.R3 \\
\hline Manuscript Type: & Revision \\
\hline Keywords: & $\begin{array}{l}\text { Mood and emotions < Attitudes, Cognitions, and Affect < Organizational } \\
\text { Behavior < Topic Areas, Stress, strain, and well-being < Attitudes, } \\
\text { Cognitions, and Affect < Organizational Behavior < Topic Areas, } \\
\text { Interpersonal communication < Organizational Communication and } \\
\text { Information Systems < Topic Areas }\end{array}$ \\
\hline Abstract: & $\begin{array}{l}\text { Small talk-short, superficial, or trivial communication not core to task } \\
\text { completion-is normative and ubiquitous in organizations. Although small } \\
\text { talk comprises one-third of adults' speech, its effects at work have been } \\
\text { discounted. Integrating theories of interaction rituals and micro-role } \\
\text { transitions, we explore how and why seemingly inconsequential } \\
\text { conversations during the workday generate meaningful effects on } \\
\text { employees' experiences. In a sample of employed adults from a } \\
\text { Northeast US University's alumni database and LinkedIn (n }=151 \text { ), we } \\
\text { used an experience sampling method (ESM) to capture within-individual } \\
\text { variation in small talk over three weeks. We also conducted a validation } \\
\text { of our daily small talk measure with Masters students from a } \\
\text { Northeastern US University ( } n=73 \text { and two samples of employed } \\
\text { adults registered with Amazon Turk ( } n=180 \text { and } n=202 \text { ). Results } \\
\text { showed that, on one hand, small talk enhanced employees' daily positive } \\
\text { social emotions at work, which translated into heightened organizational } \\
\text { citizenship behaviors (OCB) and well-being at the end of the workday; } \\
\text { on the other hand, small talk disrupted employees' ability to cognitively } \\
\text { engage in their work, which compromised their OCB. Our results also } \\
\text { showed higher levels of trait-level self-monitoring mitigated the negative } \\
\text { effects of small talk on work engagement. Combined, results suggest } \\
\text { that the polite, ritualistic, and formulaic nature of small talk is often } \\
\text { uplifting yet distracting. }\end{array}$ \\
\hline
\end{tabular}




\title{
Office Chit-Chat as a Social Ritual: The Uplifting Yet Distracting Effects of Daily Small Talk at Work
}

\author{
Jessica R. Methot \\ Rutgers University \\ and \\ University of Exeter \\ jmethot@smlr.rutgers.edu \\ Emily H. Rosado-Solomon \\ California State University Long Beach \\ emily.rosadosolomon@csulb.edu \\ Patrick E. Downes \\ Texas Christian University \\ patrick.downes@tcu.edu \\ Allison S. Gabriel \\ University of Arizona \\ asgabriel@email.arizona.edu
}

\begin{abstract}
Acknowledgements. We are grateful to Associate Editor Jessica Rodell and three anonymous reviewers for their guidance and constructive suggestions throughout the review process. We would also like to thank the members of the Positive Relationships at Work Micro-community for providing helpful comments on an earlier version of this manuscript.
\end{abstract}




\title{
OFFICE CHIT-CHAT AS A SOCIAL RITUAL: THE UPLIFTING YET DISTRACTING EFFECTS OF DAILY SMALL TALK AT WORK
}

\begin{abstract}
Small talk - short, superficial, or trivial communication not core to task completion - is normative and ubiquitous in organizational life. Although small talk comprises up to one-third of adults' speech, its effects in the workplace have been largely discounted. Yet, emerging research suggests small talk may have important consequences for employees. Integrating theories of interaction rituals and micro-role transitions, we explore how and why seemingly inconsequential conversations during the workday generate meaningful effects on employees' experiences. In a sample of employed adults recruited from a Northeast US University's alumni database and LinkedIn $(n=151)$, we used an experience sampling method (ESM) to capture within-individual variation in small talk over a three-week period. Given that we are the first to examine small talk as an episodic phenomenon, we also conducted a scale validation of our daily small talk measure with Masters students from a University in the Northeastern US $(n=73)$ and two samples of employed adults registered with Amazon Mechanical Turk $(n=180$ and $n=202)$. Using multilevel path analysis, our results showed that, on one hand, small talk enhanced employees' daily positive social emotions at work, which translated into heightened organizational citizenship behaviors (OCB) and greater well-being at the end of the workday; on the other hand, small talk disrupted employees' ability to cognitively engage in their work, which compromised their OCB. Our results also showed higher levels of trait-level self-monitoring mitigated the negative effects of small talk on work engagement. Combined, results suggest that the polite, ritualistic, and formulaic nature of small talk is often uplifting yet also distracting.
\end{abstract}

KEYWORDS: workplace communication, small talk, well-being, OCB, experience sampling method

Organizations cannot exist without communication. Indeed, workplace communicationhow employees use verbal and nonverbal messages to convey meaning (Putnam \& Mumby, 2014; Keyton, 2017) — is a necessary component of the organizing process in that it generates, maintains, and dissolves social interactions, structures and coordinates action, and creates the day-to-day reality for employees (Keyton, 2011). From the perspective of organizational scholarship, 'meaningful' communication is "talk that gets stuff done” (Coupland, 2000: 7), which is predominantly examined through exchanges that promote sensemaking (Weick, 1995), garner legitimacy (Loewenstein, Ocasio, \& Jones, 2012), and create value (Borgatti \& Foster, 2003). These can be task-oriented, instrumental, or strategic exchanges, where employees share advice, information, and feedback about how to perform one's job; they can also be expressive, 
intimate exchanges of trust and social support that help employees cope with work and nonwork stressors (Brass, 1984; Ibarra, 1992). Across research on workplace communication, the focus has been on how employees convey key ideas to one another in order to coordinate and compel action to accomplish desired objectives (Lockwood, Giorgi, \& Glynn, 2019).

Much less privileged, however, is communication whose substance is inconsequential. Indeed, small talk-short, superficial, or trivial communication that does not convey information core to task completion (Malinowski, 1972/1923) — is ubiquitous in daily organizational life. It manifests as greetings and farewells (Bullis \& Bach, 1991), chit-chat in common areas (Fayard \& Weeks, 2007), socializing before a meeting (Mirivel \& Tracy, 2005), or a transition to serious topics of discussion (Knutson \& Ayers, 1986) such as business negotiations (Shaughnessy, Mislin, \& Hentschel, 2015) or performance evaluations (Schrader, 1969). In a recent survey about conversations at work, 72 percent of employees reported discussing weekend plans or weather, 44 percent discussed sports, and 36 percent discussed primetime television (Vitukevich, 2016). Accordingly, small talk has been described as "a mere phrase of politeness [that] fulfills a function to which the meaning of its words is almost completely irrelevant. Inquiries about health, comments on the weather, affirmations of some supremely obvious state of things —all such are exchanged, not in order to inform, not in this case to connect people to action, certainly not in order to express any thought" (Malinowski, 1972/1923: 151). Thus, small talk, at its core, lacks substance. Yet, in considering daily work experiences, small talk is a normative ritual—a scripted interaction - that pervades the workplace. It is a means to build rapport and create a sense of connection by acknowledging the presence of others, and acts as a social lubricant by helping individuals transition between daily activities (Molinsky, 2013). Indeed, it is considered a breach of normative behavior to stand beside someone at the copier without greeting them or to 
dive right into a meeting without 'greasing the wheels' with small talk.

Although small talk comprises up to one-third of adults' speech (Bullis \& Bach, 1991; King, Spoeneman, Stuart, \& Beukelman, 1995) and is a fundamental workplace norm (Holmes, 2000), its effects in organizations have been largely discounted. But, research in communications (Coupland, 2000, 2003; Pullin, 2010) and social psychology (Epley \& Schroeder, 2014; Sandstrom \& Dunn, 2014) suggests small talk may yield important daily consequences for employees. Indeed, small talk softens controversial conversations, enhances mood, creates positive group climates, and facilitates a sense of belonging (Bullis \& Bach, 1991; Holmes, 2003; Huang, Yeomans, Brooks, Minson, \& Gino, 2017; Moutoux \& Porte, 1980; Sandstrom \& Dunn, 2014). At the same time, however, many people consider small talk to be pointless, draining, or distracting (Brotheridge \& Grandey, 2002; Coupland, Coupland \& Robinson, 1992), and therefore may self-impose isolation by purposefully arriving to meetings at the last minute to avoid chit-chat about the prior night's football game, or wear headphones in the office to discourage pleasantries with coworkers. Yet, research suggests individuals underestimate the positive impact of chatting with others for their positive affect and well-being, creating a social paradox whereby individuals routinely avoid small talk despite their inherent need for social connection (Boothby, Cooney, Sandstrom, \& Clark, 2018; Epley \& Schroeder, 2014).

Our research jumpstarts the conversation on small talk at work by examining why fleeting and seemingly disposable conversations during the day can have a significant impact on employee outcomes. We jointly apply theories on interaction rituals (Collins, 2004) and microrole transitions (Ashforth, 2001) to ground our expectations that small talk has meaningful and largely positive effects on employees' work experiences (Mirivel \& Tracy, 2005; Pullin, 2010): specifically, well-being at the end of the workday-individuals' subjective and emotional 
assessment of their work lives (Sonnentag, 2001) — and organizational citizenship behaviors (OCB) - the extent to which individuals go beyond formal requirements of their job to help coworkers and support their organization (Organ, 1988). On one hand, we expect small talk facilitates friendly interactions and helps employees transition between roles and activities throughout the workday (e.g., ease people into conversations, transition into or out of meetings), which generates positive social emotions at work that then enhance end-of-day well-being and OCB. On the other hand, we expect that small talk acts as a distraction that disturbs employees' focus on and engagement in their work (Jett \& George, 2003), which may subsequently aid wellbeing by allowing for restorative breaks yet compromise OCB due to a time deficiency. Finally, we theorize that individuals differ in the efficacy with which they engage in small talk during their workday, in that some may be more or less reactive to this social experience. We propose the personality trait self-monitoring will moderate these effects, such that high self-monitors will be better equipped to navigate small talk interactions and will experience heightened benefits.

Our research makes important theoretical and practical contributions to the literatures on employee communication, organizational design, and employee well-being. First, against the backdrop of well-established literatures on personal relationships (e.g., Allen \& Eby, 2012), communication networks (e.g., Monge \& Contractor, 2003), high-quality interactions (e.g., Dutton \& Heaphy, 2003), and workplace gossip (e.g., Kurland \& Pelled, 2000), we focus explicitly on small talk at work, which is considered a "peripheral mode of talk" (Coupland, 2000: 1), to establish its validity and effects on daily employee outcomes. Second, our work speaks to how individuals can ease transitions between organizational roles and replenish their resources and reduce fatigue during the workday (Ashforth, 2001). Small talk occurs frequently and episodically throughout the workday in common spaces (Fayard \& Weeks, 2007), between 
supervisors and subordinates (Moutoux \& Porte, 1980), at business events (Cunha, CabralCardoso, \& Clegg, 2008), and during breaks (Roy, 1959; Trougakos, Hideg, Cheng, \& Beal, 2014), and is a vital part of a workplace's social environment (B. Schneider, 1987). Thus, small talk provides a respite that generates positive feelings and well-being (Kim, Park, \& Headrick, 2018; Trougakos et al., 2014). Finally, our research speaks to why small talk at work may be a key condition for subsidizing positive and socially inclusive work environments. Trends toward distributed work arrangements, gig work, and flexible work schedules create physical distance between coworkers that can compromise the chit-chat that defines the workplace social environment, creating a sense of isolation and loneliness that is harmful to employees' health and well-being (O’Conner, 2017; Rockmann \& Pratt, 2015). Our work informs how daily workplace communication may aid individuals' opportunity to forge social connections (Molinsky, 2013).

\section{FOUNDATIONS AND THEORETICAL PERSPECTIVES ON SMALL TALK}

\section{Key Features of Small Talk}

In the communications literature, small talk has historically been referred to as phatic communication - the non-referential use of language to establish contact and a mood of sociability, rather than to transmit precise content, ideas, or broader meaning (Casalegno \& McWilliam, 2004; Malinowski, 1972/1923). Phatic communication, or small talk, is considered "free, aimless social discourse" (Malinowski, 1999/1926: 302), and research reveals it to be theoretically and empirically distinct from communication intended to accomplish work-related tasks. For example, Holmes (2000) and Bullis and Bach (1991) distinguish core business talkwhich includes 'on topic' talk that is transactional and maximally informative in conveying taskrelated messages — from small talk — which is relatively atopical, non-intimate, minimally informative, and has a more sociable primary function. Further, whereas core business talk is idiosyncratic, substantive, and necessarily deviates from scripted interactions (Lockwood et al., 
2019), small talk is relatively formulaic, where most dialogue involving small talk follows a conventional, normative script (K. Schneider, 1987). For example, as Hartley (2002: 174) explains, “when someone inquires 'How are you?' it would be a breach of manners to take the question as having content and actually to tell them what a bad day you've had." Rather, the conventional, scripted response is some variation of, "I'm well, thanks."

Importantly, though, these scripts contribute to the social fabric of organizations and can evolve into socially constructive rituals (Brown \& Levinson, 1987; Garfinkel, 1964). Indeed, small talk has linguistic functions that generate meaningful psychological and relational outcomes. As Coupland and colleagues (1992) explain, the underlying functions of small talk are to establish relationships and achieve transitions. These two functions are closely linked in that small talk "meaningfully sequences social encounters" by serving as a "greeting and parting ritual and patterned routine" to acknowledge the presence of others (Coupland, 2000: 5). Along these lines, we integrate theories of interaction rituals and micro-role transitions to explain why scripted and ritualistic interactions impact individuals' daily attitudes and behaviors.

\section{Application of Theoretical Perspectives to Small Talk}

Interaction ritual theory (IRT; Collins, 1993) refers to the emotional input and feedback

of individuals in face-to-face interactions. IRT is a theory of personal, ritualized interactions that involve "the voluntary performance of appropriately patterned behavior to symbolically effect or participate in life" (Rothenbuhler, 1998: 27). Rituals signal inclusion, unify individuals, and generate feelings of solidarity (Collins, 2010). There are several key ingredients of interaction rituals (Goffman, 1967). First, there is the condition of situational co-presence-that individuals assembled in the same place have an effect on one another. Second, this co-presence requires a mutual focus of attention, where encounters create a shared reality and spontaneous involvement between individuals. Finally, there is pressure toward 'social solidarity,' where individuals 
conform to normative expectations to demonstrate their membership in the encounter. As a result of these conditions, successful rituals produce feelings of belongingness, personal energy (i.e., confidence and enthusiasm in carrying out their repeated round of rituals), and targeted positive emotions (i.e., co-present individuals become caught up in an emotional rhythm; Collins, 1993). This emotional energy produces "a renewed surge of socially-based enthusiasm" (Collins, 2004: 34), such that individuals direct their energy prosocially toward others.

This core idea of IRT — that ritualized interactions have meaningful emotion-based effects on individuals — is a critical view on small talk. Yet, it does not speak to individuals' use of small talk to ease the cognitive challenges associated with transitioning between roles and activities throughout their workday. Therefore, we draw from the micro-role transitions perspective to explain how small talk aids daily role transitions and facilitates disengagement from work. During their workdays, individuals manage micro-role transitions - frequent and recurring psychological and physical movement between simultaneously held roles. These can include home-to-work transitions (e.g., parent to employee) and work-to-work transitions (e.g., peer to manager) that require disengagement from one role (i.e., role exit) and engagement in another (i.e., role entry; Ashforth, 2001). These often-abrupt transitions may be difficult to accomplish, and people frequently complain about "having to 'wear different hats' and 'shift gears"” (Ashforth, Kreiner, Fugate, \& Johnson, 2001: 261) on a daily basis. Thus, individuals seek to minimize the difficulty of role transitions (Ashforth, Kreiner, \& Fugate, 2001).

In addition to their unique contributions, there are several noteworthy complementarities between IRT and the micro-role transitions lens that help synthesize and guide our theorizing about small talk. First, IRT and micro-role transitions jointly emphasize ritualized and scripted aspects of the social environment. Specifically, they are both are grounded in the concept of rites 
of passage_-rituals that facilitate movement from one interaction or role to another (van Gennep, 1960). Rites of passage, such as promotion or retirement celebrations, can involve interactions with other individuals and the use of scripted language and behavior; they create a shared social reality and evoke emotions in interacting parties (Goffman, 1955; van Gennep, 1960). If we think of social life in organizations as a string of interactions or encounters where individuals are co-present, then small talk-such as salutations and farewells-function within IRT as transition rituals that mark when an encounter is beginning and ending (Collins, 2004). In fact, a key linguistic function of small talk is to establish, prolong, or discontinue communication (Coupland et al., 1992). It can be used to fill silences during periods of conversational liminality (Jaworski, 2000), ease into controversial conversations (Knutson \& Ayers, 1986), and punctuate conversations (Coupland, 2000; Mullany, 2006). Similarly, small talk functions within the micro-role transitions perspective as a transition script - a cognitive structure that specifies the normative sequence of behaviors and events that allow individuals to disengage from core tasks to minimize the social-psychological disruption of role transitions (Ashforth et al., 2001a). For instance, small talk acts as a social lubricant to help transition into and out of meetings (Mirivel \& Tracy, 2005) and buffer between competing roles (Ashforth et al., 2001a), and is employed to disengage from an interaction, with phrases such as, "Have a good day" or "Talk to you later."

Next, IRT and micro-role transitions share a focus on the ephemeral nature of work roles and interactions. IRT is a theory of "momentary encounters" that produce rituals of interaction that contribute to the continuity and stability of social structures (Collins, 2004: 3); similarly, micro-role transitions are short-lived, temporary states intended to satisfy social-psychological needs (Zurcher, 1970). Micro-role transitions can involve recreational activities, breaks, games, or interruptions, that act as transition bridges allowing individuals a brief 'time out' from their 
active or formal work roles to mentally disengage and conserve cognitive capacity (Ashforth \& Fried, 1988). Not surprisingly, then, small talk is prevalent at the boundaries between activities (Holmes, 2000), where role entry and exit sequences are often routinized and ephemeral. For example, individuals may engage in small talk to psychologically disengage from a meeting and transition into their lunch break. The short-term enactment of transition scripts can stimulate positive emotions and facilitate well-being (Scheff, 1979; Van Maanen \& Kunda, 1989).

Finally, both IRT and micro-role transitions evoke the notion that certain individualsspecifically those who are high on self-monitoring — are more effective than others in employing daily transition scripts. During social interactions, individuals, by and large, want to be received well, and actively construct their image to claim positive social value. Goffman (1955) refers to this as 'face-work' - when individuals try to control the impression they make on others in social encounters. Indeed, the dynamics of social encounters unfold based on whether an individual is successful in their ability 'maintain face' or whether they make a gaff that inadvertently disrupts the interaction. Similarly, individuals who are better equipped to construct their image during social interactions (i.e., individuals higher versus lower on self-monitoring) are more effective at navigating such micro-role transitions. According to Ashforth and Fried (1988), individuals who are high in self-monitoring have a high sensitivity to interpersonal cues, are adaptive to dynamic situations, and have a diverse repertoire of appropriate responses to various transitions, meaning that their ability to navigate small talk interactions should be higher.

\section{LINKING SMALL TALK TO EMPLOYEE OUTCOMES}

Drawing on IRT and micro-role transitions, we propose that small talk functions through uplifting yet distracting mechanisms to impact well-being at the end of the workday and OCB. Specifically, we theorize that small talk generates positive social emotions (an emotion-based mechanism) by fulfilling individuals' daily intrinsic needs for social cohesiveness, mutual 
recognition, and belongingness (Coupland et al., 1992). At the same time, we posit that small talk helps employees cognitively disengage from work roles (a cognition-based mechanism) by navigating the boundaries of interactions and events (Ashforth et al., 2001a; Schein, 1971; Van Maanen, 1982). We adopt an episodic, within-person view of small talk, arguing that small talk varies on a daily basis in affecting employees' positive social emotions and cognitive work engagement, which in turn affects feelings of well-being and OCB (cf. Kim et al., 2018).

\section{Uplifting Emotional Effects of Small Talk}

Personal interactions are social events in which relational partners influence each other's emotions (Hinde, 1979; Methot, Melwani, \& Rothman, 2017). According to IRT, emotions are socially constructed through daily interactions (Kitayama, Markus, \& Kurokawa, 2000; Van Kleef, 2009), and social interactions generate positive emotions that are relatively brief (Beal, Weiss, Barros, \& MacDermid, 2005; Collins, 1993). Social emotions are part of everyday talk and experience in organizational life (Cross, Baker, \& Parker, 2003), and a person's level of emotional arousal can change in response to each conversational event at work (Cross et al., 2003; Cross \& Parker, 2004; Quinn \& Dutton, 2005). Similarly, according to the micro-role transitions lens, small talk as a scripted rite of passage includes the "presence and involvement of significant others... that evoke strong emotions" (Ashforth, 2001: 11). Importantly, then, we can understand little about daily small talk without discerning the emotions - short-term, valenced affective responses to specific targets or events (Frijda, 1993; Lazarus, 1991) - that partners feel in response to each other (Ferris, Brown, Berry, \& Lian, 2008). Therefore, we expect engaging in small talk will be positively associated with employees' experiences of positive social emotions. Social emotions are discrete emotions expressed through facial expressions, vocalization, and body language that act as observable cues in social interactions (Van Kleef, 2009), with positive social emotions reflecting friendly feelings, respect, sympathy, and pride (Kitayama et al., 2000). 
There are at least two reasons why small talk generates positive social emotions. First, positive social emotions are constructed from a sense of belongingness and interpersonal engagement (Kitayama et al., 2000). Because engaging in small talk affirms one is connected to and assimilated with another in an interaction (Kitayama et al., 2000), it is a form of dialogue that creates connections and, in turn, boosts social emotions such as friendly feelings (Coupland, 2000). As individuals interact with others in a ritualistic manner, everyday encounters turn into valuing acts where individuals care for and acknowledge one another (Dutton, Debebe, \& Wrzesniewski, 2016; Goffman, 1963; Dutton \& Heaphy, 2003). We expect small talk to induce positive social emotions because it helps individuals feel 'in the loop' (Robinson, O'Reilly, \& Wang, 2013) and because it is "the kind of chit-chat people engage in simply in order to show that they recognize each other's presence" (Hudson, 1980: 109). Thus, small talk facilitates the mutual recognition, connection, and social cohesiveness that constitute positive social emotions (Beinstein, 1975; Boiger \& Mesquita, 2012; Collins, 2004; Ferris et al., 2008).

Next, small talk helps ease the transition between daily work roles and activities. Small talk acts as a transition script that provides greater predictability, while alleviating challenges associated with navigating role transitions (Ashforth et al., 2001a). Micro-role transitions theory emphasizes that transition scripts such as small talk enhance positive social emotions because the interaction involves a normative sequence of behavior that requires little effort or chance of selfdisclosure (Beinstein, 1975). Individuals engaged in a brief, light-hearted conversation are likely to experience friendly feelings associated with connecting with others, without running the risk of embarrassment or burnout. Further, research suggests low-effort activities such as small talk during the workday act as a break that helps restore individuals' personal energy coffers and produce higher levels of positive social emotions (Ashforth, 2001; Collins, 1990; Coupland, 
2000; Kim et al., 2018; Owens, Baker, Sumpter, \& Cameron, 2016; Trougakos, Beal, Green, \& Weiss, 2008). Thus, we expect engaging in scripted, ritualized interactions such as small talk heightens positive social emotions (Quinn \& Dutton, 2005).

Hypothesis 1: Daily small talk at work will be positively associated with daily positive social emotions.

We also expect that small talk will be positively associated with end-of-day well-being via positive social emotions. End-of-day well-being is a person's affective state when leaving the workplace and returning home (Diener, Suh, Lucas, \& Smith, 1999; Koopman, Lanaj, \& Scott, 2016) and captures how experiences during time away from work allow individuals to unwind (Kim et al., 2018; Sonnentag, 2001). Consistent with IRT, Heaphy and Dutton (2008) note that brief social interactions play a critical role in well-being through heightened positive emotions and physiological resourcefulness. Specifically, they suggest that positive social interactions at work leave a lasting physiological imprint that helps improve employees' mood after work. We therefore expect that small talk will improve end-of-day well-being for at least two reasons.

First, to boost well-being at the end of the day, individuals need to mentally disengage from work to lower levels of mental activation (Bennett, Bakker, \& Field, 2018; Sonnentag, 2001). Positive social emotions stemming from small talk should allow individuals to end the workday in a mental state that reduces mental preoccupation with work. Sonnentag (2001) proposed that social activities help facilitate well-being because they place little to no demands on individuals' personal resources, and found a positive link between daily voluntary social activities, such as chatting with others, and well-being prior to going to sleep after work. Because small talk eases movement in and out of task work, it enables individuals to punctuate different periods of their day and replenish personal resources spent completing work tasks (Muraven \& Baumeister, 2000; Trougakos et al., 2014). Thus, the positive social emotions generated by small 
talk yield the potential to build energetic resources that contribute to well-being at the end of the day. Second, we expect that the positive social emotions generated by small talk will generalize to the mood that individuals carry home with them. Indeed, all individuals on a daily basis have an innate and fundamental need for belonging with others and maintaining positive social relationships (Ryan \& Deci, 2008). Along these lines, Ryan, Bernstein, and Brown (2010) found that social interactions promote daily well-being through increased positive affect because they fulfill individuals' need for social connection, suggesting that the general pleasantness of and social emotions elicited by small talk exchanges spill over into individuals' mood at home. Hypothesis 2a: Daily small talk has a positive indirect relationship with feelings of end-of-day well-being through increased daily positive social emotions.

Further, we expect small talk will be positively associated with employees' OCB through its effects on positive social emotions. Because actors co-create social bonds and feelings of solidarity through small talk, their resulting behaviors should reflect a desire to contribute to the broader social structure of which they are a part. According to IRT, the positive social emotions generated by interaction rituals motivate prosocial encounters with relational partners (Collins, 2004). With respect to OCB, positive social emotions are a key ingredient in the successful maintenance of relationships; they "draw others closer" (Methot et al., 2017: 1795) by signaling cooperative and prosocial intentions (Rothman \& Magee, 2016). Indeed, a significant body of research demonstrates that positive emotions in general encourage helping behaviors (George, 1991; Isen \& Baron, 1991). In part, this is because people are motivated to help others to whom they feel emotionally connected (Grant, 2007; Korchmaros \& Kenny, 2001). Interactions that produce positive emotions seed a social exchange where individuals seek to reciprocate their elevated emotions by benefiting their coworkers (Halbesleben \& Wheeler, 2011; 2015). In this vein, $\mathrm{OCB}$ can be targeted toward specific coworkers whose interactions contributed to elevated 
positive emotions. OCB can also be targeted broadly toward the organization, given that positive emotions lead individuals to be more cooperative, prosocial, and emotionally committed to the organization (Allen \& Meyer, 1996; Carlson, Charlin, \& Miller, 1988; Ilies, Scott, \& Judge, 2006). Indeed, positive emotions are posited to broaden individuals' behavior repertoire, allowing them to act more expansively instead of having a narrow focus (Fredrickson, 2001).

Further, higher levels of positive social emotions are associated with employees' willingness to exert discretionary energy for their coworkers and organizations (Eatough, Chang, Miloslavic, \& Johnson, 2011; Quinn \& Dutton, 2005). Given that OCB involves discretionary acts that go beyond what is required by the job, a prerequisite for OCB is that individuals possess a surplus of emotional energy they are willing and able to expend to help their coworkers and the broader organization (Chang, Johnson, \& Yang, 2007). Indeed, when emotional energy is low, employees are likely to refrain from OCB in order to preserve their energetic resources for other activities (Binnewies, Sonnentag, \& Mojza, 2009; Bolino, Hsiung, Harvey, \& LePine, 2015; Trougakos et al., 2014). The emotionally energizing and restorative nature of small talk and the reciprocity these social emotions spur should carry through to increased OCB on a daily basis. Hypothesis 2b: Daily small talk has a positive indirect relationship with daily OCB through increased daily positive social emotions.

\section{Distracting Cognitive Effects of Small Talk}

Although small talk is an important social lubricant, it can also interrupt employees' work by impeding or delaying their attempts to make progress on work tasks (Jett \& George, 2003). Interruptions consume people's time, energy, and cognitive resources that could otherwise be spent on task accomplishment. From this view, small talk can hinder an individual's ability to reach a state of total involvement in a task being performed (Jett \& George, 2003) as employees chat about nonessential aspects of their day (e.g., the weather, weekend plans). Specifically, we 
expect small talk to compromise cognitive work engagement — the cognitive investment of one's complete self (energy, attention) in their work (Kahn, 1990; Rich, LePine, \& Crawford, 2010). Individuals express higher levels of engagement, in part, when they are psychologically available (i.e., have sufficient personal resources, such as time or focus, to employ and express themselves into their work roles). But, as Kahn (1990: 716) describes, interruptions can lead employees to become "too preoccupied... to invest energies in role performances." Given that small talk involves the mutual awareness and participation of both parties in the interaction (Goffman, 1967), it momentarily leads employees away from tasks and distracts from task pursuit.

Further, the micro-role transitions perspective suggests small talk should reduce cognitive engagement because its scripted, routinized nature facilitates role exit — cognitive disengagement from a role or activity (Ashforth, 2001). Small talk is a relatively automatic or mindless transition script, allowing individuals to 'go on autopilot' and cognitively detach from their work (Ashforth et al., 2001a; Ashforth \& Fried, 1988). Disengagement from a work activity, such as a meeting, may be eased by 'winding down,' where coworkers engage in small talk to cross the boundary from one activity to another (Ashforth et al., 2001a). Given that cognitive engagement requires continued behavioral momentum and absorption (Lin, Kain, \& Fritz, 2013; Schaufeli \& Bakker, 2004), the non-task-related nature of small talk likely interrupts employees' focus. Indeed, Ashforth (2001) explains that acting with effortless involvement in a scripted transition ritual such as small talk requires shifting attention and removing awareness from core tasks. Hypothesis 3: Daily small talk at work will be negatively associated with daily cognitive work engagement.

We also expect that small talk will be positively associated with end-of-day well-being through its effects on cognitive work engagement. Drawing from the micro-role transitions perspective, small talk prompts a temporary, and often predictable, break from cognitive 
engagement in one's work. These breaks have the potential to alleviate fatigue and distress, filter out irritating environmental stimuli, and highlight the need for a change of action, ultimately enhancing well-being (Jett \& George, 2003). Indeed, research highlights the importance of idle time and periods of non-taxing work such as chatting with coworkers about nonwork activities in boosting emotional well-being throughout the day (Csikszentmihalyi, 1975). For example, Roy (1959) observed that workers who integrated regular, frequent, and short interaction rituals such as casual banter with peers into their workdays felt greater enjoyment and well-being. Further, work demands can inhibit individuals' positive mood and well-being at the end of the workday (Bennett, Gabriel, Calderwood, Dahling, \& Trougakos, 2016; Bennett et al., 2018; Ryan et al., 2010), and prior work has found negative relationships between engagement and well-being (e.g., Sonnentag, Binnewies, \& Mojza, 2010). Thus, we expect the opportunity to disengage from one's work through small talk will be beneficial for personal well-being at the end of the day by aiding in personal resource and positive mood replenishment during the workday. Hypothesis 4a: Daily small talk has a positive indirect relationship with end-of-day well-being through decreased cognitive work engagement.

Yet, with respect to OCB, small talk can also detract from resources individuals could otherwise dedicate to extra-role behaviors. Work disruptions stemming from small talk can shift individuals' focus to activities that are not instrumental for work they are currently performing. These interruptions can leave a person with insufficient time and cognitive resources to engage in $\mathrm{OCB}$, which requires going beyond the scope of one's focal work requirements (Trougakos et al., 2014). Jett and George (2003: 496) explain that " $[w]$ hen an intrusion occurs, the disturbance and the subsequent social interaction that may ensue can disrupt the focused attention of a person who is working intently, reinstating time consciousness and a sense of time famine when there are many other activities to perform." Once psychological disengagement begins, it is difficult to 
fully reengage in workplace issues, even when still physically present at work (Jett \& George, 2003). Therefore, individuals sense having more responsibilities than time to complete them, decreasing the likelihood they would over-extend themselves by engaging in OCB that is beyond the scope of their work. Following the reasoning that small talk disrupts engagement in one's work, we posit small talk will indirectly hinder OCB through lower cognitive work engagement. Hypothesis 4b: Daily small talk has a negative indirect relationship with daily OCB through decreased cognitive engagement.

\section{Self-Monitoring as a Boundary Condition of the Effects of Small Talk}

We also expect these hypothesized associations have boundary conditions. Importantly, small talk is a means by which individuals negotiate personal interactions (Holmes, 2000). Given that small talk at work is a normative ritual that facilitates interactions and role transitions, individuals who are more adept at perceiving those norms and adapting their behavior to meet those norms should experience more positive outcomes. Both IRT and micro-role transitions directly assert that self-monitoring plays a key role in the fluidness with which individuals navigate daily small talk. Self-monitoring is an individual's sensitivity to situational cues as guides for behavior, concern for displaying appropriate behavior, and the effort to display such behavior (Snyder, 1987). High self-monitors are adept at recognizing, understanding, and conforming to situational cues and norms (Day \& Schleicher, 2006; Sasovova, Mehra, Borgatti, \& Schippers, 2010); actively constructing their public images (Gangestad \& Snyder, 2000; Turnley \& Bolino, 2001); crafting situations to fit their needs (Fang, Landis, Zhang, Anderson, Shaw, \& Kilduff, 2015; Fuglestad \& Snyder, 2010), and pacing conversations appropriately (Dabbs, Evans, Hopper, \& Purvis, 1980). In contrast, low self-monitors display more consistency in their communication across situations, are less adept at tailoring their behavior to meet situational norms, and run a greater risk of violating the normative script of small talk (e.g., 
sharing too much information, responding to a rhetorical question, reciprocating with a nonscripted response). In short, high self-monitors are more likely to engage in effective small talk (i.e., more normative, and thus more fluid), than are lower self-monitors, suggesting differences in effects of small talk on both positive social emotions and cognitive work engagement on a day-to-day basis.

With respect to positive social emotions, we expect the association with small talk to be more positive for high rather than low self-monitors. High self-monitors are more effective at elevating a shared sense of positive social emotions in interactions. IRT suggests that positive social emotions are transferred between parties as they receive cues about the efficacy of the interaction (Goffman, 1967). One of the hallmarks of high self-monitors is their tendency to "closely monitor the thoughts, actions, and feelings of those around them" (Sasovova et al., 2010: 641). By paying close attention to others and adapting their own behaviors in response, high self-monitors enhance the fluidity and efficacy of interactions to generate positive social emotions for interacting parties (Quinn \& Dutton, 2005). Further, according to Ashforth and colleagues (2001b), high self-monitoring should facilitate role transitions by enabling individuals to better read cues from others and adapt in a way that buffers the transition between roles and activities. Similarly, high-self monitors are adept at interpreting motives driving social interactions, and when individuals have an explanation for the meaning and function of an interruption, they produce greater positive effects on mood (Jett \& George, 2003). Thus, high self-monitors can maximize positive social emotions and energy generated through small talk.

In addition, we expect high self-monitoring will mitigate the negative association between small talk and cognitive work engagement. Engagement theory (Kahn, 1990) explains interactions with coworkers can elevate employees' perceived meaning — belief the work they do 
is important to others in the organization — and psychological safety—-that they can invest themselves in tasks without fear of negative consequences (Rich et al., 2010). For example, Kahn (1990) suggests that individuals who stay within the boundaries of appropriate behavior will feel safer and more engaged at work. Given high self-monitors are more likely to uphold interpersonal norms, they are more likely to avoid embarrassing interpersonal interactions, which prevent distractions from their work (May, Gilson, \& Harter, 2004). Further, high self-monitors place emphasis on using interactions to build relationships that might be valuable in the future (Day \& Schleicher, 2006; Sasovova et al., 2010). So, they can use small talk as an opportunity to establish relationships that alleviate fatigue or reinvigorate attention toward tasks following the small talk episode. Finally, high self-monitors should be more effective at establishing the boundaries of interactions in a way that can punctuate a conversation so they can return to their work without too much disruption. Thus, they effectively navigate competing expectations and are accustomed to moving between tasks and situations with ease. Because higher self-monitors move fluidly into and out of small talk, they should experience greater gains in meaningfulness and safety relative to low self-monitors, and should be less likely to have their cognitive engagement disrupted by small talk.

Hypothesis 5: The relationship between small talk and (a) positive social emotions and (b) cognitive work engagement will be moderated by self-monitoring. Specifically, higher (vs. lower) self-monitoring will (a) strengthen the positive association between small talk and positive social emotions, and will (b) mitigate the negative association between small talk and work engagement.

Combined, our theorizing suggests the presence of moderated mediation, such that the within-person indirect effects of daily small talk on both end-of-workday well-being and OCB via positive social emotions and cognitive work engagement will be contingent upon one's level of self-monitoring. More specifically, we posit that the indirect effect of daily small talk on each 
outcome via positive social emotions will be stronger when self-monitoring is higher (vs. lower); conversely, the indirect effect of daily small talk on each outcome via cognitive work engagement will be weaker when self-monitoring is higher (vs. lower). In sum, we propose: Hypothesis 6a-b: The positive indirect relationship of daily small talk with end of day well-being through increased daily (a) positive social emotions and (b) cognitive work engagement is stronger when self-monitoring is higher (vs. lower).

Hypothesis 7a-b: The negative indirect relationship of daily small talk with OCB through increased daily (a) positive social emotions and (b) cognitive work engagement is weaker when self-monitoring is higher (vs. lower).

\section{METHOD}

\section{Participants and Procedure}

We collected data in two phases. In the first phase, we sent a recruitment email to alumni of undergraduate and graduate degree programs in human resource management at a large public university in the Northeast United States and posted advertisements on LinkedIn. Potential participants were encouraged to forward the recruitment announcement to other qualified participants. The recruitment materials contained a description of the study and a link to an online sign-up survey. Qualifications for participating in the study were that individuals had to be employed full-time (at least 32 hours per week), work outside the home, and work a traditional schedule (e.g., arrive by 9am; leave by $5 \mathrm{pm}$ ) based on Eastern Standard Time. Employees were informed that they could receive up to $\$ 70$ for their participation in the study. The sign-up survey contained an informed consent form, the Level-2 moderator (i.e., selfmonitoring), and demographics. In total, 151 qualified employees completed the sign-up survey.

Approximately two weeks later, the 151 employees began the second phase of the study, which included three daily email surveys administered for 15 consecutive workdays. Participants completed the morning survey on average at 9:41am. This survey contained measures of small talk, positive social emotions, sleep quality, and cognitive engagement, which were control 
variables in our model (see Analytic Approach). Participants completed the afternoon survey on average at 1:43pm. This survey contained measures of small talk, which was modeled as the independent variable, as well as positive social emotions and cognitive work engagement, the mediators. Participants completed the evening survey on average at 7:42pm. This survey contained measures of end-of-day well-being and OCB, the dependent variables. Importantly, we temporally separated our variables across our surveys to better infer causality and align with ESM best practices (Gabriel, Podsakoff, Beal, Scott, Sonnentag, \& Butts, 2019). ${ }^{1}$

Twenty-six employees did not participate in the daily part of the study. Of the remaining 125 employees, 25 did not complete at least three days of surveys and were excluded from our analyses. Retaining employees who completed at least three days is needed in order to capture employees' lived experience and to appropriately model within-person variability (Gabriel, Koopman, Rosen, \& Johnson, 2018; Rosen, Koopman, Gabriel, \& Johnson, 2016). The final sample had 978 Level-1 data points out of a possible 1,500 (65.2\% response rate) from 100 employees (9.78 days per employees). Participants were mostly female (77.0\%) and Caucasian $(60.0 \%)$. The mean age was 33.6 years old $(S D=10.83)$. On average, participants worked 3.49 years in their current job $(S D=4.23)$ and 5.06 years in their current organization $(S D=6.50)$.

\footnotetext{
${ }^{1}$ We modeled afternoon small talk as our IV because it allowed us to capture a range of episodes respondents could have engaged in since arriving at work. Given the morning survey was completed, on average, at 9:41am, we would be capturing the timeframe (about an hour and a half) since employees arrive at work. The afternoon survey was completed, on average, at 1:43pm, which provided a longer timeframe (including lunch breaks) to capture small talk since the morning survey. Given employees likely take some time to become engaged in their work, assessing the co-created link between small talk and the mediators was theoretically and practically meaningful. In a supplemental analysis where we removed afternoon small talk to model morning small talk, results were not as supportive: morning small talk did not relate to either positive social emotions $(\gamma=.01, n s)$ nor cognitive work engagement $(\gamma=$ $-.01, n s)$ in the afternoon. Further, self-monitoring did not moderate the within-person relationship between morning small talk and afternoon positive social emotions $(\gamma=-.02, n s)$, nor morning small talk and afternoon cognitive work engagement $(\gamma=-.01, n s)$. Full results of this alternative path model are available from the authors upon request.
} 


\section{Daily Within-Person Measures}

With the exception of daily sleep quality, all measures were rated on a scale from 1 (not at all) to 5 (a great deal). All items for our daily constructs are included in the Appendix.

Small talk. Although we identified one existing small talk scale (Allen, LehmannWillenbrock, \& Landowski, 2014), it focuses narrowly on the content of small talk (e.g., "discussed the weather," "discussed a movie") and thus did not adequately capture the broader scope and global definition of small talk informed by the extant literature. So, we developed a scale to measure workplace small talk. We summarize the validation steps here, and provide greater detail in an online supplement to this article. In Stage 1, following Hinkin's (1995) and Hinkin and Tracey's (1999) recommendations, the authors independently generated 15 items based on a review of the literature to capture the definition of small talk: "short, superficial or trivial exchanges that do not involve task-focused exchange of information (e.g., conversations about weather, sports, weekend activities, or comments that are irrelevant or obvious)." We then solicited feedback from 10 subject matter experts who assessed the content validity of the items, and we retained the six items they judged as best representing the small talk construct.

In Stages 2 and 3, following recent guidelines established by Colquitt, Sabey, Rodell, \& Hill (2019), we collected data from three independent samples $(n=455)$ to examine the scale's factor structure and discriminant validity. First, we conducted principal components factor analysis to identify items that could be removed. We retained four items that loaded highest onto the small talk factor. Next, we conducted a principal components analysis and a series of confirmatory factor analyses using Mplus Version 8 (Muthén \& Muthén, 1998-2017) to assess the factor structure of the small talk scale and distinguish it from similar constructs (e.g., coworker support, gossip, daily interruptions); the four small talk items loaded strongly onto one factor with no cross loadings onto other factors. In a complementary procedure, we followed 
Schriesheim, Powers, Scandura, Gardiner, and Lankau's (1993) recommendations to distinguish the small talk items from related constructs (e.g., work-related communication). Participants were presented with the small talk definition and five construct definitions (one by one) related to communication episodes at work, with each definition followed by 34 randomized items. We conducted one-way ANOVAs and Duncan's Multiple Range Test (Hinkin \& Tracey 1999) to assess each item's content validity by comparing their mean ratings across each of the six construct definitions to identify whether item means were significantly different across constructs and determine which means were significantly different from one another (see Djurdjevic et al., 2017). Results of these analyses (see the online supplement) jointly support the validity of our workplace small talk scale.

In the morning survey, participants reported their level of small talk since they arrived at work that morning; in the afternoon survey employees reported the extent of their small talk with coworkers since completing the morning survey. Coefficient alpha averaged across days was .94 for the morning survey and .93 for the afternoon survey.

Positive and negative social emotions. We measured positive social emotions in the morning and afternoon with seven items from Kitayama, Mesquita, and Karasawa's (2006) social emotion scale. Participants were given a list of social emotions and asked to report the degree to which they felt each of the emotions at the present moment. Coefficient alpha averaged across days was .87 in the morning and afternoon surveys. Additionally, as a control, we measured negative social emotions with six items from Kitayama et al. (2006) in the morning (coefficient alpha averaged across days $=.89$ ) and afternoon (coefficient alpha averaged across days $=.88)$.

Cognitive work engagement. Participants reported the extent to which they experienced 
cognitive work engagement since arriving to work (morning survey) and since completing the morning survey (afternoon survey), with three items adapted from Rich et al.'s (2010) scale. Coefficient alpha averaged across days was .97 for the morning and .95 for the afternoon.

Ego depletion. As a control, participants indicated the extent to which they felt depleted in the morning and afternoon surveys with five items from Lanaj, Johnson, and Barnes (2014). Coefficient alpha averaged across days was .94 in the morning and .95 in the afternoon.

End-of-day well-being. When studying experiences such as well-being it is most appropriate to focus on specific moments, such as in the evening after work (Sonnentag, 2001). Participants were asked to reflect on their well-being at the end of each workday in the evening survey using Sonnentag's (2001) three items. Coefficient alpha averaged across days was .77.

OCB. We assessed daily OCB at the end of each day with six items from Dalal, Lam, Weiss, Welch, and Hulin's (2009) scale. Coefficient alpha averaged across days was .89.

\section{Between-Person Measure}

Self-monitoring. We measured self-monitoring using the eight positively worded items from Snyder and Gangestad's (1986) scale (e.g., Scott, Barnes, \& Wagner, 2012). Participants rated each item on a 5-point scale $(1=$ strongly disagree; 5 = strongly agree $)$, including items such as, "In different situations and with different people, I often act like very different persons" and "I'm not always the person I appear to be." Coefficient alpha was .782.

\section{Analytic Approach}

Because our data involves responses nested within individuals, we utilized multilevel path analysis in Mplus 8 (Muthén \& Muthén, 1998-2017). We first confirmed that there was

\footnotetext{
${ }^{2}$ Importantly, we ran an alternative version of the model detailed below in which we used the full 18 -item measure that included positively and negatively worded items from Snyder and Gangestad (1986). Results as reported in Figure 1 remained qualitatively unchanged, and are available from the authors upon request.
} 
sufficient within-person variability to support multilevel analyses (see Table 4). Results demonstrated that our Level-1 constructs had substantial within-person variability ranging from $33.26 \%-72.90 \%$, with $56.96 \%$ of the variability in afternoon small talk attributable to withinperson variation. Prior to hypothesis testing, we performed a multilevel confirmatory factor analysis (CFA). We modeled the items of the seven within-individual variables (small talk, positive social emotions, negative social emotions [control variable], cognitive work engagement, ego depletion [control variable], end-of-day well-being, and OCB) within-person centered at Level-1, and the items for our between-individual variable (self-monitoring) grandmean centered at Level-2. Results indicated acceptable fit $\left(\chi^{2}{ }_{(526)}=1777.25, \mathrm{CFI}=.86, \mathrm{RMSEA}\right.$ $\left.=.05, \mathrm{SRMR}_{\text {within }}=.06, \mathrm{SRMR}_{\text {between }}=.10\right)$. Of note, the CFI value is slightly lower than conventional standards (e.g., Kline, 2016). We determined through a series of alternative models that the issue largely stems from the inclusion of negative social emotions; when we removed this construct, the fit indices improved: $\chi^{2}{ }_{(355)}=1065.96, \mathrm{CFI}=.91, \mathrm{RMSEA}=.05, \mathrm{SRMR}_{\text {within }}=$ $\left..05, \mathrm{SRMR}_{\text {between }}=.10\right)$. Thus, we feel confident our hypothesized variables exhibit fit commensurate with other published work (e.g., Gabriel et al., 2018), and even our model with control variables still meets the majority of model fit conventions (that, notably, were established with models that were non-multilevel in nature; e.g., Kline, 2016). Moreover, as West, Taylor, and $\mathrm{Wu}$ (2012) noted, it is appropriate for scholars to consider model fit using a holistic assessment of all fit indices, versus relying on one (i.e., CFI).

Following recommendations (Enders \& Tofighi, 2007; Hofmann \& Gavin, 1998; Ohly, Sonnentag, Niessen, \& Zapf, 2010), we within-person centered exogenous Level-1 variables. The main benefit of within-person centering is it empirically isolates situations where individuals are above or below their personal average level (e.g., on days an employee engages in more or 
less small talk than his/her average level, what is the effect on positive social emotions?). Importantly, any unmodeled Level-2 constructs like personality or gender are uncorrelated with such variations, eliminating confounds (Enders \& Tofighi, 2007; Gabriel et al., 2019). Our Level-2 variable, self-monitoring, was grand-mean centered based on recommendations for modeling cross-level moderators (Enders \& Tofighi, 2007). All hypothesized relationships at Level-1 were modeled as random effects; the direct effects of small talk on each outcome (i.e., end-of-day well-being, OCB) and control variables were modeled as fixed effects to reduce model complexity (Wang, Liao, Zhan, \& Shi, 2011; Wang, Liu, Liao, Gong, KammeyerMueller, \& Shi, 2013). Residuals for our mediators (i.e., positive social emotions, cognitive work engagement, control variables of negative social emotions and ego depletion) and outcomes (i.e., end-of-day well-being, OCB) were allowed to covary (Kline, 2016; Preacher \& Hayes, 2008).

Insert Table 1 about here

As noted above, we included several controls in our analyses. First, we included prior (i.e., morning) assessments of small talk, positive social emotions, and cognitive work engagement as predictors end-of-day well-being and OCB. We also modeled morning positive social emotions as a predictor of afternoon positive social emotions, and morning cognitive work engagement as a predictor of afternoon cognitive work engagement. This enabled us to exclude prior levels of these constructs as alternative explanations, and to interpret these constructs as a change in their level (e.g., Gabriel, Diefendorff, \& Erickson, 2011; Lanaj, Johnson, \& Lee, 2016; Scott \& Barnes, 2011); it also provides additional evidence for our hypothesized causal direction (Beal, 2015). Second, because individuals can experience linear fluctuations in their daily states (Beal \& Ghandour, 2011; Beal \& Weiss, 2003), we controlled for effects of the day on which 
participants completed the survey (i.e., 1-15) on our mediators and endogenous variables; this variable was left uncentered in our analyses (all other controls were within-person centered).

For theoretical reasons, we also controlled for daily sleep quality on all mediating and endogenous variables, as sleep quality relates to within-person mood and well-being (e.g., Lanaj et al., 2014; Minkel et al., 2012) and has been controlled for in studies assessing factors that predict within-person OCB (e.g., Gabriel et al., 2018). We assessed sleep quality each morning with a single item, "How would you evaluate your sleep last night?” (Buysse, Reynolds, Monk, Berman \& Kupfer, 1989; $1=$ very poor to $5=$ very good). Similarly, we controlled for afternoon negative social emotions (Kitayama et al., 2006) and afternoon ego depletion (Lanaj et al., 2014) as alternative mediating pathways because small talk may create discomfort (Collins, 2004); similar to our hypothesized effects of positive social emotions and cognitive work engagement, we also controlled for the morning assessments of negative social emotions and ego depletion on afternoon negative social emotions and ego depletion, and on end-of-day well-being and OCB. Importantly, our results hold with or without controls; we retained them as a more conservative examination (Spector \& Brannick, 2011) $)^{3}$.

In testing multilevel mediation and moderated mediation, we followed Preacher, Zyphur, and Zhang (2010) and Selig and Preacher (2008) and used a Monte Carlo bootstrap approach with 20,000 simulated bias-corrected parameter estimates to calculate $95 \%$ confidence intervals (CIs) around our indirect and conditional indirect effects (e.g., Koopman et al., 2016). We specified a 1-1-1 mediation model (Preacher et al., 2010), testing the indirect effect of small talk on each outcome via positive social emotions and cognitive work engagement. Conditional

\footnotetext{
${ }^{3}$ Results of the path model without controls are available from the authors upon request.
} 
indirect effects were modeled at high and low levels of self-monitoring (1 $S D$ above and below the mean) for instances where self-monitoring emerged as a significant cross-level moderator.

\section{RESULTS}

Means, standard deviations, and correlations are displayed in Table 2. Results from our multilevel path analysis, which depicts direct and indirect effects, are shown in Figure 1.

Insert Table 2 and Figure 1 about here

Hypotheses 1 predicted that daily small talk would be positively related to positive social emotions. Results (see Figure 1) were supportive: controlling for morning levels of our mediators, daily small talk positively related to positive social emotions $(\gamma=.10, p<.01)$. Hypotheses 2a-b considered the positive indirect effect of daily small talk on (a) end-of-day well-being and (b) daily OCB via positive social emotions. Hypothesis 2a was supported: positive social emotions positively related to end-of-day well-being $(\gamma=.24, p<.01)$, and the indirect effect of daily small talk on well-being (estimate $=.024,95 \% \mathrm{CI}=.0097, .0453$ ) was significant via daily positive social emotions. Hypothesis $2 \mathrm{~b}$ was also supported: positive social emotions positively related to $\mathrm{OCB}(\gamma=.22, p<.01)$, and the indirect effect of daily small talk on OCB (estimate $=.022,95 \% \mathrm{CI}=.0103, .0391)$ was significant via positive social emotions.

Hypothesis 3 predicted that daily small talk would be negatively related to cognitive work engagement. Results were supportive: controlling for morning levels of our mediators, daily small talk was negatively related to cognitive work engagement $(\gamma=-.12, p<.05)$. Hypothesis 4a, which considered the positive indirect effect of daily small talk on end-of-day well-being via cognitive work engagement, was not supported: cognitive work engagement did not relate to end-of-day well-being $(\gamma=.00, n s)$, and the $95 \% \mathrm{CI}$ for the indirect effect of small talk on well-being via cognitive work engagement included zero (estimate $=.000,95 \% \mathrm{CI}=$ - 
$.0109, .0102)$. However, Hypothesis $4 \mathrm{~b}$ was supported, as cognitive work engagement positively related to $\mathrm{OCB}(\gamma=.08, p<.01)$, and the indirect effect of small talk on OCB via cognitive work engagement was negative and significant (estimate $=-.010,95 \% \mathrm{CI}=-.0221,-.0031$ ).

Hypothesis 5 predicted that self-monitoring would moderate the relationship between daily small talk and both (a) positive social emotions and (b) cognitive work engagement. As shown in Figure 1, the moderating effects on the link between small talk and positive social emotions was not significant $(\gamma=.05, n s)$; however, self-monitoring significantly moderated the relation between daily small talk and cognitive engagement $(\gamma=.16, p<.01)$. The interaction is illustrated in Figure 2: consistent with our theory, for high self-monitors, the negative effect of small talk on cognitive work engagement is mitigated (simple slope $=-.01, n s$ ), but for low selfmonitors, the relationship is more strongly negative (simple slope $=-.24, p<.01$ ). Thus, Hypothesis 5b, but not 5a, was supported. Given that Hypothesis 5a was not supported, we were precluded from examining the conditional indirect effects specified in Hypotheses $6 \mathrm{a}$ and $7 \mathrm{a}$ for the indirect effects of small talk on outcomes via positive social emotions. Moreover, given that cognitive work engagement did not exhibit a significant relationship with end-of-workday wellbeing, we also were precluded from exploring Hypothesis $6 \mathrm{~b}$. However, we did examine and find support for Hypothesis 7b: the indirect effect of daily small talk on OCB via cognitive work engagement was not significant at higher self-monitoring (estimate $=-.001,95 \% \mathrm{CI}=-.0090$, .0083 ) and was significant and negative at lower self-monitoring (estimate $=-.020,95 \% \mathrm{CI}=$ $.0406,-.0064)$.

Insert Figure 2 about here

\section{Supplemental Analyses}

Although we temporally separated small talk and our mediating mechanisms from our 
outcomes of interest following best practices in ESM research (Gabriel et al., 2019), small talk, positive social emotions, and cognitive work engagement were measured at the same point in time, leading to possible concerns about reverse causality. This timing of measurement allowed us to examine the very proximal effects of small talk on these two transient states that, in some ways, are likely to be co-created with small talk (e.g., Diefendorff, Gabriel, Nolan, \& Yang, 2019). Nonetheless, to further explore our data we tested a reverse causal model, with small talk mediating the effects of positive social emotions and cognitive work engagement on well-being and OCB. This analysis followed the Analytic Approach detailed above, including the same control variables and self-monitoring as a cross-level moderator. In this reverse causal model, positive social emotions were positively related to small talk $(\gamma=.35, p<.01)$, and cognitive work engagement was negatively related to small talk $(\gamma=-.16, p<.01)$. Self-monitoring did not moderate the effect of positive social emotions on small talk $(\gamma=.05, n s)$, though it did moderate the effect of cognitive work engagement on small talk $(\gamma=.10, p<.01)$. However, small talk did not significantly relate to well-being $(\gamma=.05, n s)$ or OCB $(\gamma=.03, n s)$. This analysis lends support to our theorizing—namely, that small talk generates positive social emotions and hinders cognitive work engagement, with these processes in turn affecting employees' well-being and behaviors (i.e., OCB) versus individuals reaping direct benefits from small talk at work.

\section{DISCUSSION}

Coupland (2000: 4) argues "everyday language is the "best data"”-it is the norm from which other forms of discourse deviate. Yet, small talk has been marginalized in organizational scholarship because it is considered inconsequential and purposeless. On the contrary, our study suggests the formulaic, fluid nature of small talk serves as a socially constructive ritual in daily work life (Brown \& Levinson, 1987; Coupland et al., 1992; Garfinkel, 1964). Indeed, our results show that despite the reduction in cognitive engagement and, in turn, OCB, prompted by daily 
small talk, employees who engaged in more small talk during their workday reported increased positive social emotions, which translated into greater OCB and well-being at the end of the day.

\section{Theoretical Contributions}

A core contribution of our research is to introduce the construct of small talk into management discourse and discriminate it through validation procedures from complementary forms of communication, interactions, and relationships such as gossip, friendship, or taskrelated exchanges. In the organizational sciences, research focuses on communication directed toward achieving some desired purpose (Lockwood et al., 2019). Yet, decades of research in communications and social psychology evidence that small talk is distinct from these workplace interactions because it lacks task-based or intimate exchanges (e.g., Holmes, 2000). Though small talk may lead to trusting relationships (Methot et al., 2017), and may set the stage for taskrelated exchanges, it is not expressly intended to do so. Rather, small talk is divorced from meaning, intimacy, or purpose, and can occur between people who are not closely acquainted.

Our research builds upon this foundation by recognizing that seemingly inconsequential conversations can have meaningful effects on individuals' daily work experiences. Indeed, small talk is unique because it emphasizes how "ritual solidarity is generated in the little transient interactions of everyday life, at the level of the encounter" (Collins, 1990: 28). This is a departure from traditional research on workplace interactions, which emphasizes the idiosyncrasies and active maintenance of a relationship (Walsh, Halgin, \& Huang, 2018). However, IRT and micro-role transitions provide a strong theoretical basis for our argument that brief, impersonal encounters can "pump individuals with emotional energy" (Collins, 2004: 34) and act as a recreational activity that allows individuals to disengage from their work. On one hand, small talk can fulfill employees' need for belonging, boosting their positive emotional energy and smoothing transitions between roles and activities; this translates into a greater well- 
being and energy to direct toward OCB. On the other hand, small talk is inherently 'off topic,' reducing cognitive work engagement and, in turn, the extent to which individuals have residual time and energy for OCB.

Further, this research broadens our understanding of how interaction rituals and role transitions unfold in the reality of organizations. Verbal exchanges that comprise the polite or friendly routine of interactions are a key type of ritual in everyday life (Firth, 1972; Goffman, 1981). More specifically, small talk is "a type of speech in which ties of union are created by a mere exchange of words" (Malinowski, 1972/1923: 151) that provides a routinized and predetermined script to facilitate transitions into and out of daily roles. By theorizing about small talk as transition scripts, we advance current conceptualizations of what behaviors constitute transitions and interaction rituals, and demonstrate that local conversational routines are the social fabric of organizations (Coupland, 2000). Moreover, our research theoretically advances our understanding of how energy is derived from, and invested in, our work experiences. We show that the emotional experience of receiving energy from small talk (in the form of positive social emotions) is different than the investment of energy directly to one's role performance (in the form of cognitive work engagement) — in this way, small talk may operate as a distraction point for individuals, where a shift in mental focus breaks the connection employees have with their work activities. This is consistent with both IRT and micro-role transitions, as small talk can generate a sense of intra-psychic energy, yet distract from engagement in one's work tasks.

Our work also speaks to the manner in which daily interactions can aid in individual well-being. Research suggests that social interactions can serve as work breaks (Kim et al., 2018; Jett \& George, 2003), and that these breaks allow individuals to re-energize and alleviate work stress. Indeed, our results suggest that small talk can facilitate well-being by generating positive 
social emotions, which signal that employees' day-to-day routines are successful, boosting their well-being after leaving work. That is, our findings highlight that small talk may help employees mentally disengage with their work — a key driver of well-being (Bennett et al., 2016, 2018)— inasmuch as this daily experience facilitates social emotions. Interestingly, no evidence emerged to suggest small talk positively affects well-being via cognitive work engagement, suggesting the interruptions created by small talk do not inhibit employees' well-being at the end of the day.

Finally, our work also acknowledges the joint influences of social environments and individual characteristics in understanding individual outcomes (Mischel, 1977). Specifically, we suggest small talk may have different effects for some individuals — namely, high selfmonitors - than others. Both IRT and micro-role transitions evoke the idea that high selfmonitors are more effective at navigating scripted transitions and interactions because they are better able to display normatively appropriate emotional and behavioral responses (Ashforth, 2001). Our finding that self-monitoring moderated the effect of small talk on cognitive work engagement is consistent with micro-role transitions and IRT in that high self-monitors can move fluidly between situations with less disruption. For high self-monitors, it seems small talk mitigates the distracting consequences while retaining the uplifting consequences of positive emotions, OCB, and well-being. Our research extends the growing literature integrating workplace interactions and individual differences (e.g., Fang, et al., 2015; Mehra, Kilduff, \& Brass, 2001).

\section{Practical Implications}

Our findings have useful practical implications for individuals and organizations. First, our research speaks to a growing literature on interactional features of job design spurred by the changing nature of work (e.g., adoption of virtual communication platforms, telecommuting, and the rise of the gig economy; Grant \& Parker, 2009; Kilduff \& Brass, 2010; Methot, Rosado- 
Solomon, \& Allen, 2018). Specifically, our research underscores the value of small talk in a face-to-face setting. To the extent that the shift to virtual or gig work prohibits the opportunity for small talk, it may result in lower well-being and OCB. Similarly, our research contributes to the literature on workday design, which advocates for overcoming the negative effects of workload pressure by allowing workers to have unstructured "free time" that can reduce urgency and encourage creativity (Elsbach \& Hargadon, 2006). Our findings also have implications for office design. On one hand, it is important that offices be designed so employees have the space and opportunity to engage in the spontaneous, informal interactions (Rockmann \& Pratt, 2015). Because small talk often occurs in common areas at work (Fayard \& Weeks, 2007), such spaces are crucial for promoting the positive effects derived from small talk. Similarly, organizations with remote workers are taking steps to engineer small talk between employees to combat physical separation and foster rapport (Carino, 2019). On the other hand, we found that small talk can be distracting, and thus modern trends such as open office designs, in which employees work in a communal space, may inadvertently be distracting. Small talk may be a mechanism that underlies extant findings that open office designs have negative productivity effects for employees (e.g., Brennan, Chugh, \& Kline, 2002; Evans \& Johnson, 2000).

Our findings also tie into broader implications for workplace loneliness-employees' subjective affective evaluations of whether their affiliation needs are met by people they work with and the organization they work for (Ozcelik \& Barsade, 2018). The former US Surgeon General recently described loneliness as a 'modern epidemic' (Murthy, 2017) and a burgeoning stream of research attends to organizational factors that alleviate or compensate for employee loneliness. In a recent Financial Times article, a former taxi driver who transitioned to work as an Uber driver expressed, "[At my old mini cab job], when the work was quiet, you'd go back 
into the office: all the drivers would be there, you'd mingle, you'd have a little chit-chat...

[Now] it's very, very lonely — it's just you inside your box, driving with London traffic, with all this stress. The long-term effect, honestly: it's like a bomb waiting to explode" (O'Conner, 2017). Given the negative implications of workplace loneliness for employees' well-being and job performance (Ozcelik \& Barsade, 2018) our research offers simple recommendations for how to utilize small talk to build connections with coworkers in a way that boosts well-being.

Our findings are also relevant to organizational practices directed toward socializing new employees into the workplace. To the extent that small talk creates energy, positive social emotions, and facilitates well-being, organizations might facilitate small talk to foster positive experiences for employees who are adjusting to a new work environment. Small talk between new and existing employees is likely to foster a sense of belonging and solidarity for the new employees, increasing their commitment to the organization and paving the way for improved trust and task-related cooperation between new hires and incumbents (Mak \& Chui, 2013). Small talk also has the benefit of keeping interactions relatively superficial, which can curtail the complications associated with developing stronger friendships with coworkers (Methot, LePine, Podsakoff, \& Christian, 2016). Relatedly, while many cultures have communication patterns resembling small talk (Malinowski, 1972/1923), its content differs between cultures (Meyer, 2014). Because failure to effectively engage in small talk hinders rapport and trust (Molinsky, 2013), it has been cited as a major barrier for expatriates' integration in foreign companies (Mak \& Chui, 2013) and cross-cultural negotiations (Ladegaard, 2011). Practices aimed at easing barriers in cross-cultural small talk would make a valuable contribution to expatriate management and international business, and have broader implications for diversity management. 
Admittedly, one coauthor of this study has repeatedly expressed their aversion to small talk, describing it as awkward, draining, and inauthentic (e.g., as in cases of "networking"). A second coauthor reflected on how they frequently violate the normative expectations of small talk by providing more information than would be acceptable in a passing, non-intimate conversation (e.g., oversharing in response to "How are you today?"). In discussions with others about this research, these are not uncommon experiences. Whether rooted in fears of social rejection, social anxiety, or simply not desiring or feeling equipped to feign interest in others, small talk can evoke a negative stigma. Interestingly, because our research adopts a withinindividual design which controls for between-individual differences such as extraversion and anxiety, we demonstrate that increases in small talk above one's personal mean (i.e., engaging in more small talk than one normally would on average) produces largely positive interpersonal and intrapersonal outcomes. This suggests people may "mistakenly seek solitude" by avoiding small talk for the anticipated discomfort, possibly because they overestimate negative consequences and underestimate positive consequences, of small talk (Epley \& Schroeder, 2014: 1981). Importantly, however, our research suggests the scripted nature of small talk can alleviate some uncertainty around successful small talk rituals by helping to prepare individuals with content in which they can ground a conversation (e.g., "Know any good restaurants around here?”).

\section{Limitations and Future Research}

There are several limitations of our study that highlight opportunities for future research on workplace small talk. First, while we empirically distinguished small talk from other forms of communication in our scale validation, we did not assess alternative daily communication (e.g., gossip, incivility, task-focused exchanges) in the primary study; so we are not able to pinpoint how small talk fits within the context of other interpersonal work exchanges. However, existing research has employed conversation analysis to examining dialogue line by line and demonstrate 
that small talk is often interspersed within and punctuated by, but empirically and qualitatively distinct from, informational exchanges (Bubel, 2006; Cheepen, 1988; Holmes, 2000).

Next, because of the limitations of an ESM design, we asked a small number of questions about the degree to which employees engaged in global small talk at work; we did not do a deep dive into the qualitative nature of the small talk in which individuals engaged. However, research in the communications literature suggests there may be different forms of small talk (our favorite example is "drunken banter;" Coupland et al., 1992) that could have varied effects on employees. Employees may be more energized by small talk about their weekend plans or personal hobbies than from small talk about the weather, and this energy might translate into greater well-being. Similarly, future research could examine various motivations for engaging in small talk, such as whether the intention is instrumental (e.g., networking; Casciaro, Gino, \& Kouchaki, 2014), affiliative (Hill, 1987), or simply to pass the time (Roy, 1959).

Although we temporally separated small talk and our mediating mechanisms from our outcomes, small talk, positive social emotions, and cognitive work engagement were measured at the same point in time. We wanted to assess the very proximal effects of small talk on these two transient states which, according to IRT (Collins, 2004) and recent empirical studies on felt affect (e.g., Diefendorff et al., 2019), are likely to be co-created with small talk. However, we acknowledge this leads to possible concerns about reverse causality. Our supplemental analysis addresses this concern to some degree, yet future research could explore whether morning small talk has differential effects than afternoon small talk on daily emotions and cognitions.

Similarly, all of the ratings were self-reported, which could raise concerns related to common method variance (Podsakoff, MacKenzie, Lee, \& Podsakoff, 2003). Importantly, ESM at its core is focused on the daily, lived experiences of employees (Beal, 2015), meaning 
employees themselves are best-suited to report their daily experiences and enactment of specific behaviors (i.e., OCB). In a recent overview of best practices pertaining to ESM and secondary data, Gabriel and colleagues (2019: 991) state, "the use of same-source data is perfectly acceptable when we are interested in the experiences of the focal individuals or if the phenomena of interest are such that only the focal participants would be privy to changes in them." When it comes to ratings of OCB in particular, Carpenter, Berry, and Houston (2014) showed minimal differences in the mean-levels of self- and other-reported citizenship, significant correspondence between measures of self- and other-reported citizenship, and that other-reported citizenship contributes little incremental variance beyond self-reported citizenship. Further, given our repeated assessments over several workdays, there is less of a concern that individuals are using holistic responding tendencies, as would be the concern with between-person measures.

Further, we did not determine specific partners with whom respondents engaged in small talk. Presumably, the functions of small talk differ based on the nature of a relationship between interaction partners. For instance, small talk with close friends is used to maintain relationships and transition into serious subjects (Knutson \& Ayers, 1986), whereas small talk with strangers increases positive affect (Epley \& Schroeder, 2014; Sandstrom \& Dunn, 2014). These effects may also depend on whether the focal actor is the initiator - where the individual carved out dedicated time for a social break then intends to return to work-or the receiver of the small talk-whereby an intrusion would be more disruptive to engagement because the recipient is not in control of the interaction. Teasing apart initiator from receiver could also clarify issues related to reverse causality. Although our supplemental analysis supported our hypothesized model, it is theoretically plausible that small talk — when initiated by the focal individual to take a breakmay follow cognitive engagement causally. In other words, individuals who become cognitively 
disengaged in their work during the day may walk to a friend's office and engage in small talk.

Future research could adopt a dyad-level perspective to investigate partner-specific effects.

\section{Conclusion}

Workplace small talk, despite its trivial foundations, can have vital implications for employees. We position small talk front-and-center as a form of organizational discourse by differentiating it from complementary organizational phenomena and evaluating its daily effects. Because small talk is a normative script that helps employees navigate daily social interactions, it can produce successful role transitions and interaction rituals that shape meaningful day-to-day work experiences. Taken together, our results suggest that, while small talk can distract from work engagement to compromise $\mathrm{OCB}$, it is also socially productive and restorative by boosting positive social emotions, which translates into greater well-being and OCB.

\section{REFERENCES}

Allen, T. D., \& Eby, L. T. 2012. The study of interpersonal relationships: An introduction. In L. T. Eby \& T. D. Allen (Eds.), The effect of employee attitudes, behavior, and well-being. New York: Routledge.

Allen, J. A., Lehmann-Willenbrock, N., \& Landowski, N. 2014. Linking pre-meeting communication to meeting effectiveness. Journal of Managerial Psychology, 29: 1064-1081.

Allen, N. J., \& Meyer, J. P. 1996. Affective, continuance, and normative commitment to the organization: An examination of construct validity. Journal of Vocational Behavior, 49: 252-276.

Ashforth, B. E. 2001. Role transitions in organizational life: An identity-based perspective. Mahwah, NJ: Routledge.

Ashforth, B.E., \& Fried, Y. 1988. The mindlessness of organizational behaviors. Human Relations, 41: 305-329.

Ashforth, B. E., Kreiner, G. E., \& Fugate, M. 2001a. All in a day's work: Boundaries and micro role transitions. Academy of Management Review, 25: 472-491.

Ashforth, B. E., Kreiner, G. E., Fugate, M., \& Johnson, S. A. 2001b. Micro role transitions. In B. E. Ashforth (Ed.), Role transitions in organizational life: An identity-based perspective: 258-288. Mahwah, NJ: Routledge.

Beal, D. J. 2015. ESM 2.0: State of the art and future potential of experience sampling methods in organizational research. Annual Review of Organizational Psychology and Organizational Behavior, 2: 383-407.

Beal, D. J., \& Ghandour, L. 2011. Stability, change, and the stability of change in daily workplace affect. Journal of Organizational Behavior, 32: 526-546. 
Beal, D. J., \& Weiss, H. M. 2003. Methods of ecological momentary assessment in organizational research. Organizational Research Methods, 6: 440-464.

Beal, D. J., Weiss, H. M., Barros, E., \& MacDermid, S. M. 2005. An episodic process model of affective influences on performance. Journal of Applied Psychology, 90: 1054-1068.

Beinstein, J. 1975. Small talk as social gesture. Journal of Communication, 25: 147-154.

Bennett, A. A., Bakker, A. B., \& Field, J. G. 2018. Recovery from work-related effort: A metaanalysis. Journal of Organizational Behavior, 39: 262-275.

Bennett, A. A., Gabriel, A. S., Calderwood, C., Dahling, J. J., \& Trougakos, J. P. 2016. Better together? Examining profiles of employee recovery experiences. Journal of Applied Psychology, 101: 1635-1654.

Binnewies, C., Sonnentag, S., \& Mojza, E. J. 2009. Daily performance at work: Feeling recovered in the morning as a predictor of day-level job performance. Journal of Organizational Behavior, 30: 67-93.

Boiger, M., \& Mesquita, B. 2012. The construction of emotion in interactions, relationships, and cultures. Emotion Review, 4(3): 221-229.

Bolino, M. C., Hsiung, H.-H., Harvey, J., \& LePine, J. A. 2015. "Well, I'm tired of tryin'!" Organizational citizenship behavior and citizenship fatigue. Journal of Applied Psychology, 100: 56-74.

Boothby, E. J., Cooney, G., Sandstrom, G. M., \& Clark, M. S. 2018. The liking gap in conversations: Do people like us more than we think? Psychological Science, 29: 1742-1756.

Borgatti, S. P., \& Foster, P. C. 2003. The network paradigm in organizational research: A review and typology. Journal of Management, 29: 991-1013.

Brass, D. J. 1984. Being in the right place: A structural analysis of individual influence in an organization. Administrative Science Quarterly, 29: 518-539.

Brennan, A., Chugh, J. S., \& Kline, T. 2002. Traditional versus open office design: A longitudinal field study. Environment and Behavior, 34: 279-299.

Brotheridge, C. M., \& Grandey, A. A. 2002. Emotional labor and burnout: Comparing two perspectives of "people work." Journal of Vocational Behavior, 60: 17-39.

Brown, P., \& Levinson, S. C. 1987. Politeness: Some universals in language usage (Vol. 4). Cambridge, UK: Cambridge University Press.

Bubel, C. 2006. "How are you?" "I'm hot": An interactive analysis of small talk sequences in British-German telephone sales. In K. Buhrig \& J. D. ten Thije (Eds.), Beyond misunderstanding: Linguistic analyses of intercultural communication: 245-259. Philadelphia, PA: John Benjamins Publishing.

Bullis, C., \& Bach, B. W. 1991. An explication and test of communication network content and multiplexity as predictors of organizational identification. Western Journal of Communication, 55: 180-197.

Buysse, D. J., Reynolds, C. F., Monk, T. H., Berman, S. R., \& Kupfer, D. J. 1989. The Pittsburgh Sleep Quality Index: A new instrument for psychiatric practice and research. Psychiatry Research, 28: 193-213.

Carino, M. M. (host). 2019, May 6. Remote offices find creative workarounds as more Americans stay home [Audio podcast]. Marketplace Morning Report, NPR. https://www.marketplace.org/2019/05/06/remote-offices-find-creative-workarounds-moreamericans-stay-home/.

Carlson, M., Charlin, V., \& Miller, N. 1988. Positive mood and helping behavior: A test of six hypotheses. Journal of Personality and Social Psychology, 55: 211-229. 
Carpenter, N. C., Berry, C. M., \& Houston, L. 2014. A meta-analytic comparison of self-reported and other-reported organizational citizenship behavior. Journal of Organizational Behavior, 35: 547-574.

Casalegno, F., \& McWilliam, I. M. 2004. Communication dynamics in technological mediated learning environments. International Journal of Instructional Technology and Distance Learning, 1(11): 15-33.

Casciaro, T., Gino, F., \& Kouchaki, M. 2014. The contaminating effects of building instrumental ties: How networking can make us feel dirty. Administrative Science Quarterly, 59: 705-735.

Chang, C. H., Johnson, R. E., \& Yang, L. Q. 2007. Emotional strain and organizational citizenship behaviours: A meta-analysis and review. Work \& Stress, 21: 312-332.

Cheepen, C. 1988. The predictability of informal conversation. London, UK: Pinter Pub Ltd.

Colquitt, J. A., Sabey, T. B., Rodell, J. R., \& Hill, E. (2019). Content validation benchmarks: Evaluation criteria for definitional correspondence and definitional distinctiveness. Journal of Applied Psychology, 104: 1243-1265.

Collins, R. 1990. Stratification, emotional energy, and transient emotions. In T. D. Kemper (Ed.), Research agendas in the sociology of emotions: 27-57. Albany, NY: State University of New York Press.

Collins, R. 1993. Emotional energy as the common denominator of rational action. Rationality and Society, 5: 203-230.

Collins, R. 2004. Interaction ritual chains. Princeton, NJ: Princeton University Press.

Collins, R. 2010. The Micro-sociology of religion: Religious practices, collective and individual. The Association of Religion Data Archives, http://www.thearda.com/rrh/papers/guidingpapers/Collins.pdf.

Coupland, J. 2000. Small talk. New York: Pearson Education.

Coupland, J. 2003. Small talk: Social functions. Research on Language and Social Interaction, 36(1): 1-6.

Coupland, J., Coupland, N., \& Robinson, J. D. 1992. "How are you”? Negotiating phatic communion. Language in Society, 21: 207-230.

Csikszentmihalyi, M. 1975. Beyond boredom and anxiety. San Francisco, CA: Jossey-Bass.

Cross, R., Baker, W., \& Parker, A. 2003. What creates energy in organizations? MIT Sloan Management Review, 44(4): 51-57.

Cross, R., \& Parker, A. 2004. Charged up: Creating energy in organizations. Journal of Organizational Excellence, 23(4): 3-14.

Cunha, M. P. E, Cabral-Cardoso, C., \& Clegg, S. 2008. Manna from heaven: The exuberance of food as a topic for research in management and organization. Human Relations, 61: 935-963.

Dabbs, J. M., Evans, M. S., Hopper, C. H., \& Purvis, J. A. 1980. Self-monitors in conversation: What do they monitor? Journal of Personality and Social Psychology, 39: 278-284.

Dalal, R. S., Lam, H., Weiss, H. M., Welch, E. R., \& Hulin, C. L. 2009. A within-person approach to work behavior and performance: Concurrent and lagged citizenshipcounterproductivity associations, and dynamic relationships with affect and overall job performance. Academy of Management Journal, 52: 1051-1066.

Day, D. V. \& Schleicher, D. J. 2006. Self-monitoring at work: A motive-based perspective. Journal of Personality, 74: 685-714.

Diefendorff, J. M., Gabriel, A. S., Nolan, M. T., \& Yang, J. 2019. Emotion regulation in the context of customer mistreatment and felt affect: An event-based profile approach. Journal of Applied Psychology, 104: 965-983. 
Diener, E., Suh, E. M., Lucas, R. E., \& Smith, H. L. 1999. Subjective well-being: Three decades of progress. Psychological Bulletin, 125, 276-302.

Djurdjevic, E., Stoverink, A. C., Klotz, A. C., Koopman, J., da Motta Veiga, S. P., Yam, K. C., \& Chiang, J. T. J. 2017. Workplace status: The development and validation of a scale. Journal of Applied Psychology, 102, 1124-1147.

Dutton, J. E., Debebe, G., \& Wrzesniewski, A. 2016. Being valued and devalued at work: A social valuing perspective. In B. A. Bechky \& K. D. Elsbach (Eds.), Qualitative Organizational Research: Best Papers from the Davis Conference on Qualitative Research: 9-51. Charlotte, NC: Information Age Publishing.

Dutton, J. E., \& Heaphy, E. D. 2003. The power of high-quality connections. In J. E. Dutton, R. E. Quinn, \& K. S. Cameron (Eds.), Positive organizational scholarship: Foundations of a new discipline: 263-278. San Francisco, CA: Berrett-Koehler Publishers.

Eatough, E. M., Chang, C.-H., Miloslavic, S. A., \& Johnson, R. E. 2011. Relationships of role stressors with organizational citizenship behavior: A meta-analysis. Journal of Applied Psychology, 96: 619-632.

Elsbach, K. D. \& Hargadon, A. B. 2006. Enhancing creativity through "mindless" work: A framework of workday design. Organization Science, 17: 470-483.

Enders, C. K. \& Tofighi, D. 2007. Centering predictor variables in cross-sectional multilevel models: A new look at an old issue. Psychological Methods, 12(2): 121-138.

Epley, N. \& Schroeder, J. 2014. Mistakenly seeking solitude. Journal of Experimental Psychology: General, 143: 1980-1999.

Evans, G. W. \& Johnson, D. 2000. Stress and open-office noise. Journal of Applied Psychology, 85: 779-783.

Fang, R., Landis, B., Zhang, Z., Anderson, M. H., Shaw, J. D. \& Kilduff, M. 2015. Integrating personality and social networks: A meta-analysis of personality, network position, and work outcomes in organizations. Organization Science, 26: 1243-1260.

Fayard, A., \& Weeks, J. 2007. Photocopies and water-coolers: The affordances of informal interaction. Organization Studies, 28: 605-634.

Ferris, D. L., Brown, D. J., Berry, J. W., \& Lian, H. 2008. The development and validation of the workplace ostracism scale. Journal of Applied Psychology, 93: 1348-1366.

Firth, R. 1972. Verbal and bodily rituals of greeting and parting. In J. S. La Fontaine (Ed.), The interpretation of ritual: 1-38. New York: Routledge.

Fredrickson, B. L. 2001. The role of positive emotions in positive psychology: The broaden-andbuild theory of positive emotions. American Psychologist, 56(3): 218-226.

Frijda, N. H. 1993. Moods, emotion episodes, and emotions. In M. Lewis \& J. M. Haviland (Eds.), Handbook of emotions: 381-403. New York: Guilford Press.

Fuglestad, P. T., \& Snyder, M. 2010. Status and the motivational foundations of self-monitoring. Social and Personality Psychology Compass, 4: 1031-1041.

Gabriel, A. S., Diefendorff, J. M., \& Erickson, R. J. 2011. The relations of daily task accomplishment satisfaction with changes in affect: A multilevel study in nurses. Journal of Applied Psychology, 96: 1095-1104.

Gabriel, A. S., Koopman, J., Rosen, C. C., \& Johnson, R. E. 2018. Helping others or helping oneself? An episodic examination of the behavioral consequences of helping at work. Personnel Psychology, 71: 85-107. 
Gabriel, A. S., Podsakoff, N. P., Beal, D. J., Scott, B. A., Sonnentag, S., Butts, M. 2019. Experience sampling methods: A discussion of critical trends and considerations for scholarly advancement. Organizational Research Methods, 22: 969-1006.

Gangestad, S. W., \& Snyder, M. 2000. Self-monitoring: Appraisal and reappraisal. Psychological Bulletin, 126: 530-555.

Garfinkel, H. 1964. Studies of the routine grounds of everyday activities. Social Problems, 11(3): 225-250.

George, J. M. 1991. State or trait: Effects of positive mood on prosocial behaviors at work. Journal of Applied Psychology, 76: 299-307.

Goffman, E. 1955. On face-work: An analysis of ritual elements in social interaction. Psychiatry: Journal for the Study of Interpersonal Processes, 18: 213-231.

Goffman, E. 1963. Stigma: Notes on the management of spoiled identity. New York: Simon \& Schuster.

Goffman, E. 1967. Interaction ritual: Essays on face-to-face interaction. Oxford, England: Aldine.

Goffman, E. 1981. Forms of talk. Philadelphia, PA: University of Pennsylvania Press.

Grant, A. M. 2007. Relational job design and the motivation to make a prosocial difference. Academy of Management Review, 32: 393-417.

Grant, A. M., \& Parker, S. K. 2009. Redesigning work design theories: The rise of relational and proactive perspectives. Academy of Management Annals, 3: 317-375.

Halbesleben, J. R., \& Wheeler, A. R. 2011. I owe you one: Coworker reciprocity as a moderator of the day-level exhaustion-performance relationship. Journal of Organizational Behavior, 32: 608-626.

Halbesleben, J. R., \& Wheeler, A. R. 2015. To invest or not? The role of coworker support and trust in daily reciprocal gain spirals of helping behavior. Journal of Management, 41: $1628-1650$.

Hartley, J. 2002. Communication, cultural and media studies: The key concepts, 3rd ed. New York: Routledge.

Heaphy, E. D., \& Dutton, J. E. 2008. Positive social interactions and the human body at work: Linking organizations and physiology. Academy of Management Review, 33: 137-162.

Hill, C. A. 1987. Affiliation motivation: People who need people... but in different ways. Journal of Personality and Social Psychology, 52: 1008-1018.

Hinde, R. A. 1979. Towards understanding relationships. London: Academic Press.

Hinkin, T. R. 1995. A review of scale development practices in the study of organizations. Journal of Management, 21: 967-988.

Hinkin, T. R., \& Tracey, J. B. 1999. An analysis of variance approach to content validation. Organizational Research Methods, 2: 175-186.

Hofmann, D. A., \& Gavin, M. B. 1998. Centering decisions in hierarchical linear models: Implications for research in organizations. Journal of Management, 24: 623-641.

Holmes, J. 2000. Doing collegiality and keeping control at work: Small talk in government departments. In J. Coupland (Ed.), Small talk: 32-61. New York: Routledge.

Holmes, J. 2003. Small talk at work: Potential problems for workers with an intellectual disability. Research on Language and Social Interaction, 36(1): 65-84.

Huang, K., Yeomans, M., Brooks, A. W., Minson, J., \& Gino, F. 2017. It doesn't hurt to ask: Question-asking increases liking. Journal of Personality and Social Psychology, 113: 430-452.

Hudson, R. A. 1980. Sociolinguistics. Cambridge: Cambridge University Press. 
Ibarra, H. 1992. Homophily and differential returns: Sex differences in network structure and access in an advertising firm. Administrative Science Quarterly, 37: 422-447.

Ilies, R., Scott, B. A., \& Judge, T. A. 2006. The interactive effects of personal traits and experienced states on intraindividual patterns of citizenship behavior. Academy of Management Journal, 49: 561-575.

Isen, A. M., \& Baron, R. A. 1991. Positive affect as a factor in organizational-behavior. Research in Organizational Behavior, 13: 1-53.

Jaworski, A. (2000). Silence and small talk. In J. Coupland (Ed.), Small talk: 110-132. New York: Pearson Education.

Jett, Q. R., \& George, J. M. 2003. Work interrupted: A closer look at the role of interruptions in organizational life. Academy of Management Review, 28: 494-507.

Kahn, W. A. 1990. Psychological conditions of personal engagement and disengagement at work. Academy of Management Journal, 33: 692-724.

Keyton, J. 2011. Communication and organizational culture: A key to understanding work eperiences. Thousand Oaks, CA: Sage Publications, Inc.

Keyton, J. 2017. Communication in organizations. Annual Review of Organizational Psychology and Organizational Behavior, 40: 501-526.

Kilduff, M., \& Brass, D. J. 2010. Organizational social network research: Core ideas and key debates. Academy of Management Annals, 4: 317-357.

Kim, S., Park, Y., \& Headrick, L. 2018. Daily micro-breaks and job performance: General work engagement as a cross-level moderator. Journal of Applied Psychology, 103: 772-786.

King, J., Spoeneman, T., Stuart, S., \& Beukelman, D. 1995. Small talk in adult conversations: Implications for AAC vocabulary selection. Augmentative and Alternative Communication, 11(4): 260-264.

Kitayama, S., Markus, H. R., \& Kurokawa, M. 2000. Culture, emotion, and well-being: Good feelings in Japan and the United States. Cognition \& Emotion, 14(1): 93-124.

Kitayama, S., Mesquita, B., \& Karasawa, M. 2006. Cultural affordances and emotional experience: Socially engaging and disengaging emotions in Japan and the United States. Journal of Personality and Social Psychology, 91: 890-903.

Kline, R. B. 2016. Principles and practice of structural equation modeling (4th ed.). New York, NY: Guilford Press.

Knutson, P., \& Ayers, J. 1986. An exploration of the function of small talk in friendship relationships. Journal of the Northwest Communication Association, 14: 4-18.

Koopman, J., Lanaj, K., \& Scott, B. A. 2016. Integrating the bright and dark sides of OCB: A daily investigation of the benefits and costs of helping others. Academy of Management Journal, 59: 414-435.

Korchmaros, J. D. \& Kenny, D. A. 2001. Emotional closeness as a mediator of the effect of genetic relatedness on altruism. Psychological Science, 12: 262-265.

Kurland, N. B., \& Pelled, L. H. 2000. Passing the word: Toward a model of gossip and power in the workplace. Academy of Management Review, 25: 428-438.

Ladegaard, H. J. 2011. Negotiation style, speech accommodation, and small talk in Sino-Western business negotiations: A Hong Kong case study. Intercultural Pragmatics, 8: 197-226.

Lanaj, K., Johnson, R. E., \& Barnes, C. M. 2014. Beginning the workday yet already depleted? Consequences of late-night smartphone use and sleep. Organizational Behavior and Human Decision Processes, 124: 11-23. 
Lanaj, K., Johnson, R. E., \& Lee, S. M. 2016. Benefits of transformational behaviors for leaders: A daily investigation of leader behaviors and need fulfillment. Journal of Applied Psychology, 101: 237-252.

Lazarus, R. S. 1991. Emotion and adaptation. New York: Oxford University Press.

Lin, B. C., Kain, J. M., \& Fritz, C. 2013. Don't interrupt me! An examination of the relationship between intrusions at work and employee strain. International Journal of Stress

Management, 20: 77-94.

Lockwood, C., Giorgi, S., \& Glynn, M. A. 2019. "How to do things with words": Mechanisms bridging language and action in management research. Journal of Management, 45: 7-34.

Loewenstein, J., Ocasio, W., \& Jones, C. 2012. Vocabularies and vocabulary structure: A new approach linking categories, practices, and institutions. Academy of Management Annals, 6: 41-86.

Mak, B. C. N., \& Chui, H. L. 2013. A cultural approach to small talk: A double-edged sword of sociocultural reality during socialization into the workplace. Journal of Multicultural Discourses, 8(2): 118-134.

Malinowski, B. 1999/1926. On Phatic Communion. In A. Jaworski and N. Coupland (Eds), The Discourse Reader: 302-305. London and New York: Routledge.

Malinowski, B. 1972/1923. Phatic communion. Communication in face-to-face interaction. Harmondworth: Penguin Books.

May, D. R., Gilson, R. L., \& Harter, L. M. 2004. The psychological conditions of meaningfulness, safety and availability and the engagement of the human spirit at work. Journal of Occupational and Organizational Psychology, 77(1): 11-37.

Mehra, A., Kilduff, M., \& Brass, D. J. 2001. The social networks of high and low self-monitors: Implications for workplace performance. Administrative Science Quarterly, 46: 121-146.

Methot, J. R., LePine, J. A., Podsakoff, N. P., \& Christian, J. S. 2016. Are workplace friendships a mixed blessing? Exploring tradeoffs of multiplex relationships and their associations with job performance. Personnel Psychology, 69: 311-355.

Methot, J. R., Melwani, S., \& Rothman, N. B. 2017. The space between us: A social-functional emotions view of ambivalent and indifferent workplace relationships. Journal of Management, 43: 1789-1819.

Methot, J. R., Rosado-Solomon, E. H., \& Allen, D. G. 2018. Network architecture of human capital: A relational identity perspective. Academy of Management Review, 43: 723-748.

Meyer, E. 30 May, 2014. One reason cross-cultural small talk is so tricky. Harvard Business Review. Available at https://hbr.org/2014/05/one-reason-cross-cultural-small-talk-is-sotricky.

Minkel, J. D., Banks, S., Htaik, O., Moreta, M. C., Jones, C. W., McGlinchey, E. L., ... \& Dinges, D. F. 2012. Sleep deprivation and stressors: Evidence for elevated negative affect in response to mild stressors when sleep deprived. Emotion, 12: 1015-1020.

Mirivel, J. C., \& Tracy, K. 2005. Premeeting talk: An organizationally crucial form of talk. Research on Language and Social Interaction, 38(1): 1-34.

Mischel, W. 1977. The interaction of person and situation. In D. Magnusson \& N. S. Endler (Eds.), Personality at the crossroads: Current issues in interactional psychology: 333-352. New York: Halsted Press.

Molinsky, A. L. 27 February, 2013. The big challenge of American small talk. Harvard Business Review. Available at https://hbr.org/2013/02/the-big-challenge-with-america. 
Monge, P. R., \& Contractor, N. S. 2003. Theories of communication networks. New York: Oxford University Press.

Moutoux, D., \& Porte, M. 1980. Small talk in industry. Journal of Business Communication, 17(2): 3-11.

Mullany, L. 2006. "Girls on tour": Politeness, small talk, and gender in managerial business meetings. Journal of Politeness Research, 2: 55-77.

Muraven, M., \& Baumeister, R. F. 2000. Self-regulation and depletion of limited resources: Does self-control resemble a muscle? Psychological Bulletin, 126: 247-259.

Murthy, V. 2017. Work and the loneliness epidemic: Reducing isolation at work is good business. Harvard Business Review. Available at https://hbr.org/cover-story/2017/09/workand-the-loneliness-epidemic.

Muthén, L. K., \& Muthén, B. O. 1998-2017. Mplus User's Guide. Seventh Edition. Los Angeles, CA: Muthén \& Muthén.

O'Conner, S. Sept 22, 2017. Driven to despair - the hidden costs of the gig economy. Financial Times. https://www.ft.com/content/749cb87e-6ca8-11e7-b9c7-15af748b60d0.

Ohly, S., Sonnentag, S., Niessen, C., \& Zapf, D. 2010. Diary studies in organizational research. Journal of Personnel Psychology, 9: 79-93.

Organ, D. W. 1988. Organizational citizenship behavior: The good soldier syndrome.

Lexington, MA: Lexington Books.

Owens, B., Baker, W., Sumpter, D. M., \& Cameron, K. 2016. Relational energy at work: Implications for job engagement and job performance. Journal of Applied Psychology, 101: $35-49$.

Ozcelik, H., \& Barsade, S. G. 2018. No employee an island: Workplace loneliness and job performance. Academy of Management Journal, 61: 2343-2366.

Podsakoff P.M., MacKenzie S.B., Lee J., \& Podsakoff N.P. 2003. Common method biases in behavioral research: A critical review of the literature and recommended remedies. Journal of Applied Psychology, 88: 879-903.

Preacher, K. J., \& Hayes, A. F. 2008. Asymptotic and resampling strategies for assessing and comparing indirect effects in multiple mediator models. Behavior Research Methods, 40: 879-891.

Preacher, K. J., Zyphur, M. J., \& Zhang, Z. 2010. A general multilevel SEM framework for assessing multilevel mediation. Psychological Methods, 15: 209-233.

Pullin, P. 2010. Small talk, rapport, and international communicative competence: Lessons to learn from BELF. Journal of Business Communication, 47(4): 455-476.

Putnam, L. L., \& Mumby, D. K. 2014. The SAGE handbook of organizational communication. Thousand Oaks, CA: Sage Publications, Inc.

Quinn, R. W., \& Dutton, J. E. 2005. Coordination as energy-in-conversation. Academy of Management Review, 30: 36-57.

Rich, B. L., LePine, J. A., \& Crawford, E. R. 2010. Job engagement: Antecedents and effects on job performance. Academy of Management Journal, 53: 617-635.

Robinson, S. L., O’Reilly, J., \& Wang, W. 2013. Invisible at work: An integrated model of workplace ostracism. Journal of Management, 39: 203-231.

Rockmann, K. W., \& Pratt, M. G. 2015. Contagious offsite work and the lonely office: The unintended consequences of distributed work. Academy of Management Discoveries, 1: $150-164$. 
Rothenbuhler, E. W. 1998. Ritual communication: From everyday conversation to mediated ceremony. Thousand Oaks, CA: Sage.

Rothman, N. B., \& Magee, J. C. 2016. Affective expressions in groups and inferences about members' relational well-being: The effects of socially engaging and disengaging emotions. Cognition \& Emotion, 30: 150-166.

Rosen, C. C., Koopman, J., Gabriel, A. S., \& Johnson, R. E. 2016. Who strikes back? A daily investigation of when and why incivility begets incivility. Journal of Applied Psychology, 101: 1620-1634.

Roy, D. F. 1959. "Banana time": Job satisfaction and informal interaction. Human Organization, 18(4): 158-168.

Ryan, R. M., Bernstein, J. H., \& Brown, K. W. 2010. Weekends, work, and well-being: Psychological need satisfactions and day of the week effects on mood, vitality, and physical symptoms. Journal of Social and Clinical Psychology, 29(1): 95-122.

Ryan, R. M., \& Deci, E. L. 2008. From ego depletion to vitality: Theory and findings concerning the facilitation of energy available to the self. Social and Personality Psychology Compass, 2: 702-717.

Sandstrom, G. M., \& Dunn, E. W. 2014. Is efficiency overrated?: Minimal social interactions lead to belonging and positive affect. Social Psychological and Personality Science, 5: 437-442.

Sasovova, Z., Mehra, A., Borgatti, S. P., \& Schippers, M. C. 2010. Network churn: The effects of self-monitoring personality on brokerage dynamics. Administrative Science Quarterly, 55: 639-670.

Schaufeli, W. B., \& Bakker, A. B. 2004. Job demands and job resources and their relationship with burnout and engagement: A multiple-sample study. Journal of Organizational Behavior, 25: 293-315.

Scheff, T. J. 1979. Catharsis in healing, ritual, and drama. Berkeley, CA: Univ of California Press.

Schein, E. H. 1971. The individual, the organization, and the career: A conceptual scheme. Journal of Applied Behavioral Science, 7: 401-426.

Schneider, B. 1987. The people make the place. Personnel Psychology, 40: 437-453.

Schneider, K. 1987. Topic selection in phatic communication. Multilingua - Journal of CrossCultural and Interlanguage Communication, 6: 247-256.

Schrader, A. W. 1969. Let's abolish the annual performance review. Human Resource Management, 8: 20-28.

Schriesheim, C. A., Powers, K. J., Scandura, T. A., Gardiner, C. C., \& Lankau, M. J. 1993. Improving construct measurement in management research: Comments and a quantitative approach for assessing the theoretical content adequacy of paper-and-pencil survey-type instruments. Journal of Management, 19: 385-417.

Scott, B. A., \& Barnes, C. M. 2011. A multilevel field investigation of emotional labor, affect, work withdrawal, and gender. Academy of Management Journal, 54: 116-136.

Scott, B. A., Barnes, C. M., \& Wagner, D. T. 2012. Chameleonic or consistent? A multilevel investigation of emotional labor variability and self-monitoring. Academy of Management Journal, 55: 905-926.

Selig, J. P., \& Preacher, K. J. 2008. Monte Carlo method for assessing mediation: An interactive tool for creating confidence intervals for indirect effects. [Computer software]. Available from http://quantpsy.org 
Shaughnessy, B. A., Mislin, A. A., \& Hentschel, T. 2015. Should he chitchat? The benefits of small talk for male versus female negotiators. Basic and Applied Social Psychology, 37: $105-117$.

Snyder, M. 1987. Public appearances, private realities: The psychology of self-monitoring. New York, NY: W. H. Freeman.

Snyder, M., \& Gangestad, S. 1986. On the nature of self-monitoring: Matters of assessment, matters of validity. Journal of Personality and Social Psychology, 51(1): 125-139.

Sonnentag, S. 2001. Work, recovery activities and well-being. Journal of Occupational Health Psychology, 6(3): 196-210.

Sonnentag, S., Binnewies, C., \& Mojza, E. J. 2010. Staying well and engaged when demands are high: The role of psychological detachment. Journal of Applied Psychology, 95: 965-976.

Spector, P. E., \& Brannick, M. T. 2011. Methodological urban legends: The misuse of statistical control variables. Organizational Research Methods, 14: 287-305.

Trougakos, J. P., Beal, D. J., Green, S. G., \& Weiss, H. M. 2008. Making the break count: An episodic examination of recovery activities, emotional experiences, and positive affective displays. Academy of Management Journal, 51: 131-146.

Trougakos, J. P., Hideg, I., Cheng, B. H., \& Beal, D. J. 2014. Lunch breaks unpacked: The role of autonomy as a moderator of recovery during lunch. Academy of Management Journal, 57: 405-421.

Turnley, W. H., \& Bolino, M. C. 2001. Achieving desired images while avoiding undesired images: Exploring the role of self-monitoring in impression management. Journal of Applied Psychology, 86: 351-360.

Van Gennep, A. 1960. The rites of passage. Chicago: University of Chicago Press.

Van Kleef, G. A. 2009. How emotions regulate social life: The emotions as social information (EASI) model. Current Directions in Psychological Science, 18(3): 184-188.

Van Maanen, J. 1982. Boundary crossings: Major strategies of organizational socialization and their consequences. In R. Katz (Ed.), Career issues in human resource management: 85 115. Englewood Cliffs, NJ: Prentice-Hall.

Van Maanen, J., \& Kunda, G. 1989. Real feelings. Emotional expression and organizational culture. In L.L. Cummings, B.M. Staw (Eds.), Research in Organizational Behaviour, vol. 11: 43-102. Greenwich, CT: JAI Press.

Vitukevich, N. 2016. Water cooler talk: Weather, "Game of Thrones", football dominate office chatter. Office Pulse. Retrieved from http://officepulse.captivate.com/watercooler-talkwhat-professionals-are-discussing-at-the-of.

Walsh, I. J., Halgin, D. S., \& Huang, Z. 2018. Making old friends: Understanding the causes and consequences of maintaining former coworker relationships. Academy of Management Discoveries, 4: 410-428.

Wang, M., Liao, H., Zhan, Y., \& Shi, J. 2011. Daily customer mistreatment and employee sabotage against customers: Examining emotion and resource perspectives. Academy of Management Journal, 54: 312-334.

Wang, M., Liu, S., Liao, H., Gong, Y., Kammeyer-Mueller, J., \& Shi, J. 2013. Can't get it out of my mind: Employee rumination after customer mistreatment and negative mood in the next morning. Journal of Applied Psychology, 98: 989-1004.

Weick, K. E. 1995. Sensemaking in organizations. Thousand Oaks, CA: Sage Publications. 
West, S. G., Taylor, A. B., \& Wu, W. 2012. Model fit and model selection in structural equation modeling. In R. H. Hoyle (Ed.), Handbook of structural equation modeling: 209-231. New York, NY: Guilford Press.

Zurcher, L. A. 1970. The "friendly" poker game: A study of an ephemeral role. Social Forces, 49(2): 173-186.

TABLE 1 PERCENTAGE OF WITHIN- AND BETWEEN-INDIVIDUAL VARIANCE IN DAILY CONSTRUCTS

\begin{tabular}{lccc}
\hline & $\begin{array}{c}\text { Within- } \\
\text { individual } \\
\text { variance }\left(\boldsymbol{e}^{2}\right)\end{array}$ & $\begin{array}{c}\text { Between- } \\
\text { individual } \\
\text { variance }\left(\boldsymbol{r}^{2}\right)\end{array}$ & $\begin{array}{c}\text { \% of within- } \\
\text { individual } \\
\text { variance }\end{array}$ \\
\hline Sleep quality (AM) & .667 & .248 & $72.90 \%$ \\
Small talk (AM) & .607 & .321 & $65.41 \%$ \\
Positive social emotions (AM) & .281 & .537 & $34.35 \%$ \\
Cognitive work engagement (AM) & .766 & .503 & $60.35 \%$ \\
Negative social emotions (AM) & .183 & .271 & $40.31 \%$ \\
Ego depletion (AM) & .468 & .581 & $44.61 \%$ \\
Small talk (PM) & .589 & .445 & $56.96 \%$ \\
Positive social emotions (PM) & .235 & .626 & $27.29 \%$ \\
Cognitive work engagement (PM) & .601 & .356 & $62.80 \%$ \\
Negative social emotions (PM) & .143 & .287 & $33.26 \%$ \\
Ego depletion (PM) & .413 & .706 & $36.91 \%$ \\
End-of-day well-being (EV) & .531 & .381 & $58.22 \%$ \\
OCB (EV) & .357 & .592 & $37.62 \%$ \\
\hline
\end{tabular}

Note. The percentage of variance within-individuals was calculated as $\mathrm{e}^{2} /\left(\mathrm{e}^{2}+\mathrm{r}^{2}\right)$. Small Talk (AM), positive social emotions (AM), cognitive work engagement (AM), negative social emotions (PM), and ego depletion (PM) were used as control variables to model change in our focal constructs. 
TABLE 2 MEANS, STANDARD DEVIATIONS, AND CORRELATIONS AMONG STUDY VARIABLES

\begin{tabular}{|c|c|c|c|c|c|c|c|c|c|c|c|c|c|c|c|c|c|}
\hline & $M$ & $S D$ & 1 & 2 & 3 & 4 & 5 & 6 & 7 & 8 & 9 & 10 & 11 & 12 & 13 & 14 & 15 \\
\hline \multicolumn{18}{|l|}{ Level 1} \\
\hline 1. Sleep Quality & 3.29 & .96 & -- & & & & & & & & & & & & & & \\
\hline 2. Day & -- & -- & .03 & -- & & & & & & & & & & & & & \\
\hline 3. Small talk (AM) & 2.05 & .97 & .03 & -.01 & $(.94)$ & & & & & & & & & & & & \\
\hline 4. Positive social emotions (AM) & 2.41 & .92 & $.11^{* *}$ & $-.16^{* *}$ & $.32 * *$ & $(.87)$ & & & & & & & & & & & \\
\hline 5. Cognitive work engagement (AM) & 3.08 & 1.13 & .01 & $-.10^{* *}$ & -.05 & $.15^{* *}$ & $(.97)$ & & & & & & & & & & \\
\hline 6. Negative social emotions (AM) & 1.40 & .69 & $-.13 * *$ & -.02 & .01 & -.06 & -.03 & $(.89)$ & & & & & & & & & \\
\hline 7. Ego depletion (AM) & 1.86 & 1.02 & $-.30 * *$ & -.05 & -.03 & $-.15 * *$ & $-.16^{* *}$ & $.42 * *$ & (.94) & & & & & & & & \\
\hline 8. Small talk (PM) & 2.42 & 1.03 & .05 & $.07 *$ & $.19 * *$ & $.07^{*}$ & -.03 & -.04 & -.02 & $(.93)$ & & & & & & & \\
\hline 9. Positive emotions (PM) & 2.42 & .91 & $.09 * *$ & -.06 & $.14^{* *}$ & $.45^{* *}$ & $.08^{*}$ & $-.08^{*}$ & $-.12 * *$ & $.22 * *$ & $(.87)$ & & & & & & \\
\hline 10. Cognitive work engagement (PM) & 3.40 & .97 & -.01 & $-.09 * *$ & -.01 & $.13^{* *}$ & $.25^{* *}$ & -.02 & $-.06^{*}$ & $-.09 * *$ & $.23^{* *}$ & $(.95)$ & & & & & \\
\hline 11. Negative social emotions (PM) & 1.39 & .68 & $-.08^{*}$ & -.04 & -.05 & $-.13 * *$ & .04 & $.62 * *$ & $.30^{* *}$ & $-.09 * *$ & $-.20 * *$ & -.06 & $(.88)$ & & & & \\
\hline 12. Ego depletion (PM) & 1.98 & 1.03 & $-.09 * *$ & .01 & $-.07 *$ & $-.19 * *$ & $-.12 * *$ & $.29 * *$ & $.47 * *$ & $-.07^{*}$ & $-.23 * *$ & $-.22 * *$ & $.38^{* *}$ & $(.95)$ & & & \\
\hline 13. End-of-day well-being (EV) & 3.58 & .94 & $.12 * *$ & .02 & $.09 * *$ & $.15^{* *}$ & $.08^{*}$ & $-.19 * *$ & $-.18^{* *}$ & $.14^{* *}$ & $.21^{* *}$ & .03 & $-.23 * *$ & $-.19 * *$ & $(.77)$ & & \\
\hline 14. OCB (EV) & 3.05 & .99 & -.01 & -.06 & $.10^{* *}$ & $.21^{* *}$ & $.06^{*}$ & -.02 & -.02 & $.07^{*}$ & $.20^{* *}$ & $.14 * *$ & -.05 & $-.10 * *$ & $.17^{* *}$ & (.89) & \\
\hline \multicolumn{18}{|l|}{ Level 2} \\
\hline 15. Self-monitoring & 2.70 & .74 & -.19 & -.01 & .05 & -.05 & $-.34^{* *}$ & $.32 * *$ & $.32 * *$ & .09 & .03 & $-.25^{*}$ & $.33^{* *}$ & $.33^{* *}$ & $-.26^{* *}$ & -.11 & (.77) \\
\hline
\end{tabular}

Note. Level-1 (day-level) $n=978$; Level-2 (person-level) $n=100$. AM = morning survey measure; PM = afternoon survey measure; $\mathrm{EV}=$ evening survey measure. Correlations for within-individual (Level-1) variables reflect within person-centered associations. ${ }^{*} p<.05,{ }^{* *} p<.01$. 
FIGURE 1 MULTILEVEL PATH ANALYSIS RESULTS

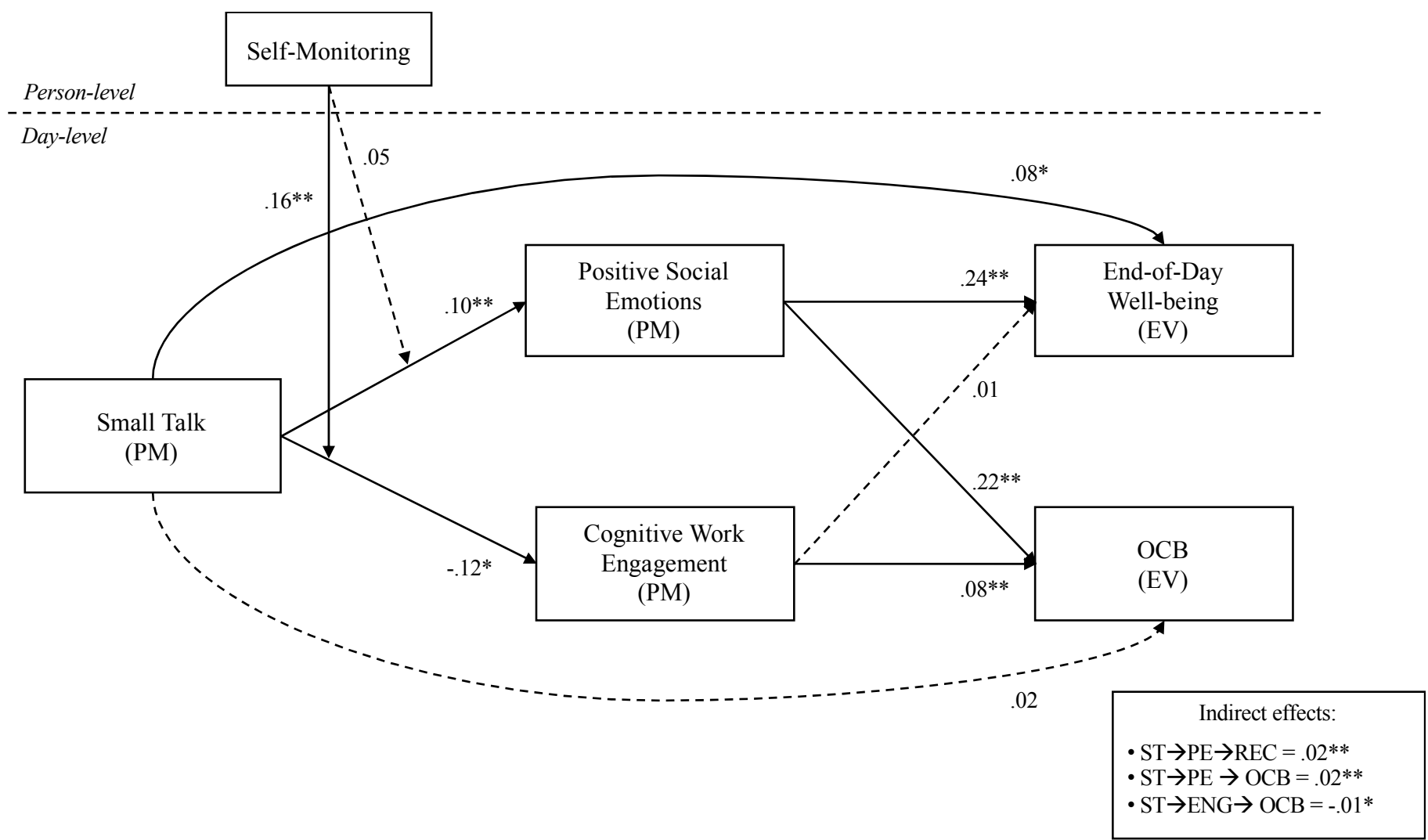

Note. Level-1 (day-level) $n=978$; Level-2 (person-level) $n=100 . \mathrm{PM}=$ afternoon survey measure; EV = evening survey measure. Using formulas provided by Snijders and Bosker (1999), our model accounted for $6 \%$ of the withinperson variance in positive social emotions, $11 \%$ of the within-person variance in cognitive work engagement, $31 \%$ of the within-person variance in end-of-day well-being, and $28 \%$ of the within-person variance in OCB.

${ }^{*} p<.05, * * p<.01$. 


\section{FIGURE 2 CROSS-LEVEL MODERATING EFFECT OF SELF-MONITORING ON THE RELATIONSHIP BETWEEN DAILY SMALL TALK AND COGNITIVE WORK ENGAGEMENT}

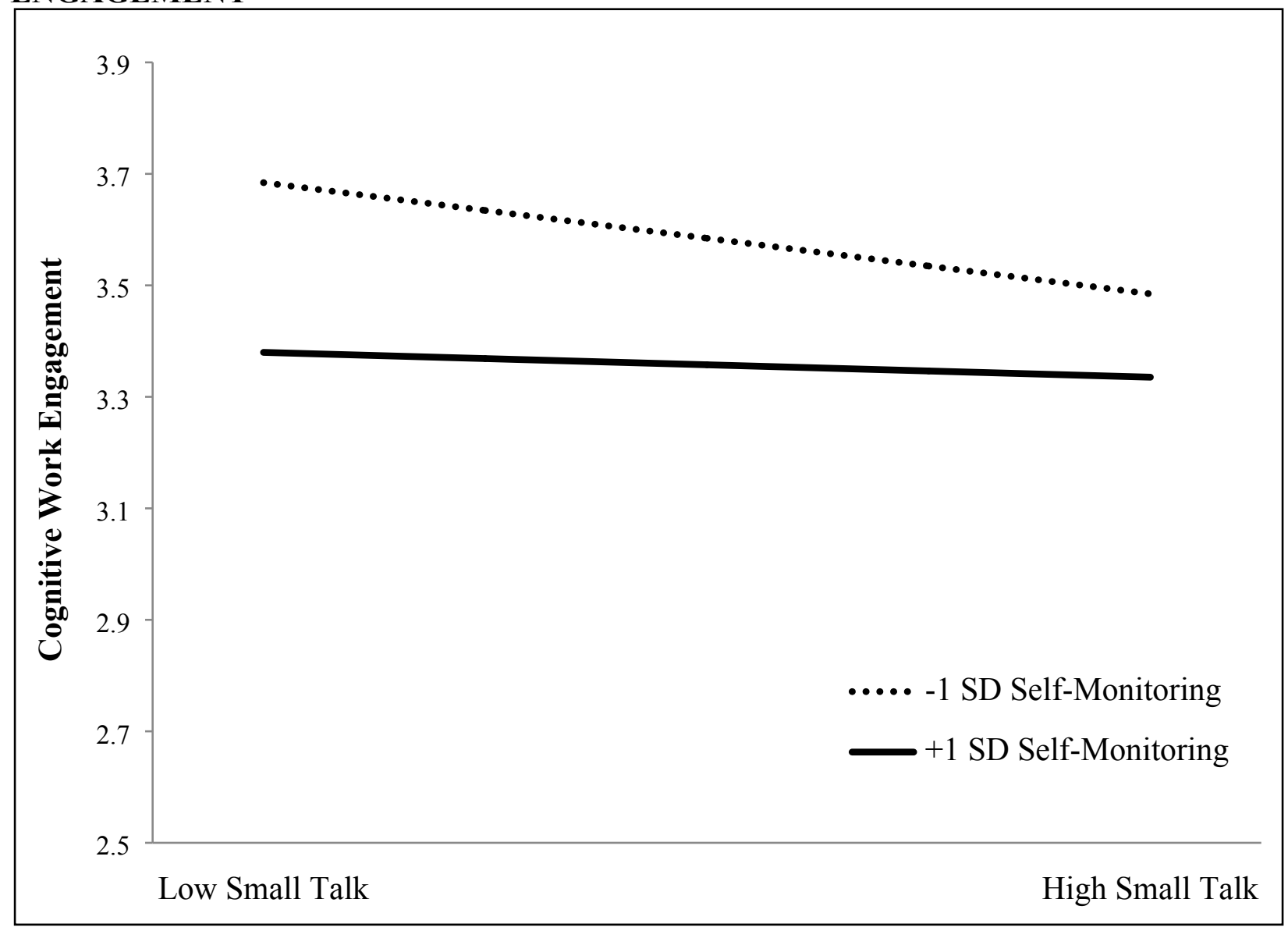

Note. The relationship between daily small talk and daily cognitive work engagement is negative and significant at low levels of self-monitoring (simple slope $=-.24, p<.01$ ) and non-significant at high levels of self-monitoring (simple slope $=-.01, n s$ ). 


\section{Daily Small Talk (developed for the current study)}

1. I had 'water cooler' talk with my coworkers.

2. My coworkers and I had small talk.

3. I chatted with my coworkers about superficial topics.

4. I communicated with my coworkers about trivial matters.

\section{Positive Social Emotions (Kitayama et al., 2006)}

1. Friendly feelings

2. Close feelings

3. Respect

4. Sympathy

5. Proud

6. Superior

7. On top of the world

Negative Social Emotions (Kitayama et al., 2006)

1. Guilt

2. Indebted

3. Ashamed

4. Sulky feelings

5. Frustration

6. Angry

Cognitive Work Engagement (adapted from Rich et al., 2010)

1. I gave my full attention to my job.

2. My mind was focused on my work.

3. I concentrated completely on my work.

Ego Depletion (Lanaj et al., 2014)

1. I feel drained

2. My mind feels unfocused

3. It would take a lot of effort for me to concentrate on something

4. My mental energy is running low

5. I feel like my willpower was gone

\section{End-of-day Well-being (Sonnentag, 2001)}

1. I was in a good mood when coming home from work.

2. I felt tense when coming home from work. (reverse coded)

3. I was in a good mood at the end of the workday. 


\title{
OCB (Dalal et al., 2009)
}

1. I went out of my way to be a good employee.

2. I was respectful of other people's needs.

3. I displayed loyalty to my organization.

4. I praised or encouraged someone.

5. I volunteered to do something that was not required.

6. I showed genuine concern for others.

\begin{abstract}
Jessica R. Methot (jmethot@smlr.rutgers.edu) is an Associate Professor of Human Resource Management in the School of Management and Labor Relations at Rutgers University and a Distinguished Research Professor of Management at the University of Exeter, UK. She earned her Ph.D. from the University of Florida. Her research focuses on the multidimensionality of social networks in organizations and their functional and dysfunctional consequences.
\end{abstract}

Emily H. Rosado-Solomon (emily.rosadosolomon@csulb.edu) is an Assistant Professor in the Department of Management and HRM at California State University, Long Beach's College of Business. She received her Ph.D. from Rutgers University School of Management and Labor Relations. Her research interests include employee communication, interpersonal relationships, workplace diversity, and mental health.

Patrick E. Downes (patrick.downes@tcu.edu) is an assistant professor in the management and leadership department of the Neeley School of Business at Texas Christian University. He received his Ph.D. from the University of Iowa. His research interests include employees' social contexts (e.g., social networks, teams, and job demands), motivation, and research methods.

\begin{abstract}
Allison S. Gabriel (asgabriel@email.arizona.edu) is an Associate Professor and Robbins Fellow in the Department of Management and Organizations at the Eller College of Management at the University of Arizona. She received her Ph.D. in Industrial-Organizational Psychology from the University of Akron. Her research broadly focuses on emotions at work, interpersonal stressors, employee recovery, and employee well-being, with an emphasis on within-person processes and person-centered methodologies.
\end{abstract}

